\title{
Direct Recording of Dendrodendritic Excitation in the Olfactory Bulb: Divergent Properties of Local and External Glutamatergic Inputs Govern Synaptic Integration in Granule Cells
}

\author{
R. Todd Pressler and Ben W. Strowbridge \\ Department of Neurosciences, Case Western Reserve University, Cleveland, Ohio 44106
}

The olfactory bulb contains excitatory principal cells (mitral and tufted cells) that project to cortical targets as well as inhibitory interneurons. How the local circuitry in this region facilitates odor-specific output is not known, but previous work suggests that GABAergic granule cells plays an important role, especially during fine odor discrimination. Principal cells interact with granule cells through reciprocal dendrodendritic connections that are poorly understood. While many studies examined the GABAergic output side of these reciprocal connections, little is known about how granule cells are excited. Only two previous studies reported monosynaptically coupled $\mathrm{mitral} /$ granule cell connections and neither attempted to determine the fundamental properties of these synapses. Using dual intracellular recordings and a custom-built loose-patch amplifier, we have recorded unitary granule cell EPSPs evoked in response to mitral cell action potentials in rat (both sexes) brain slices. We find that the unitary dendrodendritic input is relatively weak with highly variable release probability and short-term depression. In contrast with the weak dendrodendritic input, the facilitating cortical input to granule cells is more powerful and less variable. Our computational simulations suggest that dendrodendritic synaptic properties prevent individual principal cells from strongly depolarizing granule cells, which likely discharge in response to either concerted activity among a large proportion of inputs or coactivation of a smaller subset of local dendrodendritic inputs with coincidence excitation from olfactory cortex. This dual-pathway requirement likely enables the sparse mitral/granule cell interconnections to develop highly odor-specific responses that facilitate fine olfactory discrimination.

Key words: brain slice; interneurons; local circuitry; olfactory bulb; paired recordings; synaptic transmission

Significance Statement

The olfactory bulb plays a central role in converting broad, highly overlapping, sensory input patterns into odor-selective population responses. How this occurs is not known, but experimental and theoretical studies suggest that local inhibition often plays a central role. Very little is known about how the most common local interneuron subtype, the granule cell, is excited during odor processing beyond the unusual anatomical arraignment of the interconnections (reciprocal dendrodendritic synapses). Using paired recordings and two-photon imaging, we determined the properties of the primary input to granule cells for the first time and show that these connections bias interneurons to fire in response to spiking in large populations of principal cells rather than a small group of highly active cells.

\section{Introduction}

The olfactory bulb $(\mathrm{OB})$ plays a central role in processing olfactory sensory input originating in receptor neurons. Through a combination of intrinsic properties and local synaptic circuits,

\footnotetext{
Received July 18, 2017; revised Sept. 22, 2017; accepted 0ct. 16, 2017.

Author contributions: R.T.P. and B.W.S. designed research; R.T.P. performed research; R.T.P. and B.W.S. analyzed data; R.T.P. and B.W.S. wrote the paper.

This work was supported by National Institutes of Health Grants R01-DC-004285 to B.W.S. and R03-DC-013641 to R.T.P. We thank Chris Ford and Hannah Arnson for helpful discussions and critical comments on this manuscript. We also thank Boris Barbour for helpful advice on the design of the loose patch-clamp amplifier used in study.
}

principal cells in the $\mathrm{OB}$ generate firing patterns that reflect differential patterns of activity in glomerular input channels (Shepherd, 2003). The primary excitatory drive to each bulb principal neuron [mitral cells (MCs) and tufted cells (TCs)] arises from a restricted set of sensory receptor neurons that express one odorant receptor subtype. Mitral and tufted cells also receive potent

Correspondence should be addressed to Dr. Ben W. Strowbridge, Department of Neurosciences, Case Western Reserve University School of Medicine, 10900 Eudlid Avenue, Cleveland, 0H 44106. E-mail: bens@case.edu. DOI:10.1523/JNEUROSCI.2033-17.2017

Copyright $\odot 2017$ the authors $\quad 0270-6474 / 17 / 3711774-15 \$ 15.00 / 0$ 
inhibitory input that functions to modulate their response to activity in their cognate subgroup of receptor neurons (White et al., 1992; Fukunaga et al., 2012). Through these local connections, the odor-evoked firing pattern of MCs and TCs is shaped to reflect network activity patterns, not just the activity of the one receptor subclass that innervates their apical dendrites (Guthrie et al., 1993; Friedrich and Laurent, 2001; Soucy et al., 2009).

How inhibitory local circuit activity shapes principal cell firing patterns is not known but likely involves input from granule cells (GCs), the most common GABAergic interneuron in the $\mathrm{OB}$, as well as a group of interneurons that resides in the glomerular (input) layer of the $\mathrm{OB}$ and that functions to regulate sensory excitation of MCs (Shepherd, 2003; Murphy et al., 2005; Najac et al., 2015). Granule cells interact with both MCs and TCs through stereotyped reciprocal dendrodendritic (DD) synapses (Rall et al., 1966; Jahr and Nicoll, 1980; Isaacson and Strowbridge, 1998). While multiple studies have reported properties of the GC feedback IPSP onto MCs (Isaacson and Strowbridge, 1998; Schoppa et al., 1998; Chen et al., 2000; Dietz and Murthy, 2005; Balu and Strowbridge, 2007), much less is known about how GCs are excited through dendrodendritic synapses. Only one report quantified GC responses assayed in MC/GC paired recording (Isaacson, 2001), which used voltage-clamp [not action potential (AP) based] stimuli and was focused on the glutamate receptor makeup in GCs. Relatively little is known about the physiological response evoked in GCs from mitral/tufted cell spiking or about the short-term plasticity at this pathway.

Granule cells receive excitatory input from $\sim 65$ presynaptic principal OB cells through dendrodendritic synapses (Greer, 1987). Differences in unitary response amplitudes and short-term plasticity at these inputs will dramatically affect synaptic integration, leading to pronounced differences in both the frequency and temporal patterning of neuron discharges (Abbott and Regehr, 2004). Direct measurements of these properties from paired intracellular recordings are technically challenging because of the sparse connectivity in this brain region (Kato et al., 2013). Therefore, it is not known whether GCs can be driven to spike in response to relatively few powerful inputs or, instead, only via "mass action" from concerted discharges in many presynaptic MCs and TCs. There is indirect evidence, focal extracellular stimulation along the distal dendrites of voltage-clamped GCs (Balu et al., 2007), that excitatory dendrodendritic synapses depress. However, large-amplitude nondepressing excitatory postsynaptic responses are evoked by glutamate release at axonal terminals formed by the same bulbar principal cells when they synapse onto pyramidal cells in piriform cortex (Hasselmo and Bower, 1990; Franks and Isaacson, 2006; Suzuki and Bekkers, 2006; Stokes and Isaacson, 2010), raising the possibility that previous extracellular stimulation studies overestimated short-term depression.

Using both whole-cell (WC) intracellular and loose-patch (LP) paired recordings from monosynaptically coupled mitral/ granule cell pairs, we find that single APs evoke small-amplitude, highly variable, unitary EPSPs. Dendrodendritic EPSPs showed modest paired pulse depression at physiological firing frequencies but then strongly depress in response to the third and subsequent presynaptic APs. Together, the small, variable unitary responses and the short-term plasticity present at dendrodendritic excitatory synapses suggest that near-synchronous activation of a substantial fraction $(\sim 50 \%)$, of all the presynaptic dendrodendritic excitatory inputs, would be required to trigger spiking in GCs. These results suggest that dendrodendritic excitatory inputs likely function to determine a relatively depolarizing "tone" rather than reliably triggering spikes. Instead, GC spikes are likely triggered by bursts of activity in piriform cortical neurons that coincide with sensory-evoked periods of dendrodendritic EPSP summation. Working together, local bulbar and cortical feedback excitatory pathways may function to generate sparse but highly odor-specific GC discharges that facilitate olfactory discrimination by interrupting sensory-driven excitation of mitral and tufted cells.

\section{Materials and Methods}

Slice preparation. Horizontal OB slices $300 \mu \mathrm{m}$ thick were made from ketamine-anesthetized postnatal day 14 (P14) to P25 Sprague Dawley rats of both sexes, as previously described (Balu et al., 2007; Pressler et al., 2013). Slices were incubated for $30 \mathrm{~min}$ at $30^{\circ} \mathrm{C}$ and then at room temperature until use. All experiments were carried out in accordance with the guidelines approved by the Case Western Reserve University Animal Care and Use Committee. Slices were placed in a recording chamber and superfused with oxygenated artificial CSF (ACSF) at a rate of $1.5 \mathrm{ml} / \mathrm{min}$. Recordings were made between $29^{\circ} \mathrm{C}$ and $32^{\circ} \mathrm{C}$. The ACSF consisted of the following (in mM): $124 \mathrm{NaCl}, 3 \mathrm{KCl}, 1.23 \mathrm{NaH}_{2} \mathrm{PO}_{4}, 1.2 \mathrm{MgSO}_{4}, 26$ $\mathrm{NaHCO}_{3}, 10$ dextrose, and $2.5 \mathrm{CaCl}_{2}$, equilibrated with $95 \% \mathrm{O}_{2} / 5 \% \mathrm{CO}_{2}$. All drugs were added to the submerged recording chamber by changing the external solution source.

Whole-cell recordings. All whole-cell patch-clamp recordings were made with Axopatch 1C or 1D Amplifiers (Molecular Devices) using borosilicate glass pipettes (WPI) of impedances ranging from 2 to $5 \mathrm{M} \Omega$ pulled on a P-97 Pipette Puller (Sutter Instruments). Under WC currentclamp conditions, recording electrodes contained the following (in $\mathrm{mM}$ ): $140 \mathrm{~K}$-methylsulfate (MP Biochemicals), $4 \mathrm{NaCl}, 10 \mathrm{HEPES}, 0.2$ EGTA, 4 MgATP, $0.3 \mathrm{Na}_{3} \mathrm{GTP}$, and 10 phosphocreatine, $\mathrm{pH} 7.3$ and $\sim 290 \mathrm{mOsm}$. Whole-cell recordings were low-pass filtered at $5 \mathrm{kHz}$ (FLA-01, Cygus Technology) and digitized at either $10 \mathrm{kHz}$ (dual WC paired recordings) or $40 \mathrm{kHz}$ (LP/WC paired recordings) using an ITC-18 data acquisition interface (HEKA) simultaneously sampling data acquisition interface using custom software written in Visual Basic (Microsoft). Intracellular records of mitral and granule cell spiking were not clipped in the illustrations.

Loose patch-clamp recording. LP clamp recordings were made using a custom-built patch-clamp amplifier with fast-response dynamics and large stimulus capacity. The stimulus voltages required to trigger spikes through loose-patch recordings are typically beyond the capacity of traditional patch-clamp amplifiers. A specially designed current preamplifier with large voltage compliance solves this problem and represents an improvement over blindly stimulating the patch since it enables the operator to determine whether the stimulus pulse actually triggered an AP on each trial.

The custom-built amplifier used for the loose cell-attached recordings in this study was adapted from the study by Barbour and Isope, 2000 and is described in a separate report (Strowbridge and Pressler, 2017). Both the input-stage operational amplifier (OPA604, Burr Brown/TI) and the differential output amplifier (INA106, Burr Brown/TI) were mounted on a custom-printed circuit board and enclosed within a small aluminum box connected to the circuit ground. A $20 \mathrm{M} \Omega$ feedback resistor set the transimpedance gain and the stimulus pulse amplitude was controlled by a 10-turn potentiometer. Pulse timing was controlled by an optically isolated digital output line from the ITC-18 and connected to a single-pole, double-throw analog switch (HI-5043, Intersil). The output of the analog switch was buffered using a low-noise operational amplifier (OP27, Analog Devices). Recording pipettes contained $124 \mathrm{~mm} \mathrm{NaCl}, 3$ mM KCl, and 10 mm HEPES, pH 7.4.

We operated the sample clock on the ITC-18 at $40 \mathrm{kHz}$ during LP recordings and typically used $50 \mu$ s duration steps from 0 to $0.2-0.75 \mathrm{~V}$ to trigger APs in MCs. Since the threshold stimulus required to trigger APs varied considerably from cell to cell, and often during the recording, we did not attempt to record the step voltage in each experiment. The output from the LP amplifier was low-pass filtered at $10 \mathrm{kHz}$ and amplified two to five times (FLA-01, Cygnus Technologies) before being digitized by the ITC-18. The response from a single failure trial (where no AP was evoked in the MC) acquired on a previous trial was subtracted from $\mathrm{LP}$ responses shown in Figure 2. If the presynaptic MC was spontane- 
ously active (an issue in only one-third of LP recordings), we restricted the GC postsynaptic responses analyzed to those that occurred at least $200 \mathrm{~ms}$ after a spontaneous MC spike.

DIC and two-photon imaging. Slices were imaged using infrared differential interference contrast (IR-DIC) optics on a Olympus BX51WI upright microscope. Transmitted light was restricted to $710-790 \mathrm{~nm}$ using a bandpass interference filter placed above the microscope field stop. DIC images were captured using a frame-transfer CCD camera (Cohu) and displayed on a high-resolution monochrome analog monitor (Sony). Individual neurons were visualized using IR-DIC video microscopy before attempting either WC or LP recording. Live two-photon imaging was performed using a custom-built laser-scanning system, as described in previous publications (Pressler and Strowbridge, 2006; Balu et al., 2007; Gao and Strowbridge, 2009). Since the two-photon system used in this study had only a single detection channel (one nonremovable emission filter and photomultiplier tube), we used the same fluorescent dye (Alexa Fluor 594; $100 \mu \mathrm{M}$ ) in both presynaptic and postsynaptic neurons. In image reconstructions, we identified MC and GC processes by connecting visualized dendritic segments to the soma region across a series of $z$-stack montages. The $z$-axis on this system was not motorized so that frames within image stacks are presented in the order of their $z$-position but at slightly variable focus depth increments (typically $1-2 \mu \mathrm{m}$ between frames). Spine head surface area was approximated using an ellipse based on the two largest orthogonal diameters. Neuronal cell type was determined based on IR-DIC morphology and soma laminar location. Cell type classification was confirmed in a subset of experiments using twophoton reconstructions, as described in the text.

Focal synaptic stimulation. Focal stimulation of presynaptic processes near the proximal apical and basal dendrites was performed under twophoton guidance using the same method used in previous reports (Balu et al., 2007; Gao and Strowbridge, 2009). A patch pipette filled with saline solution containing Alexa Fluor $594(100 \mu \mathrm{M})$ dissolved in $124 \mathrm{~mm} \mathrm{NaCl}$, $3 \mathrm{~mm} \mathrm{KCl}$, and $10 \mathrm{~mm}$ HEPES, pH 7.4, was placed near $(5-10 \mu \mathrm{m})$ the visualized GC dendrite. The stimulating electrode was connected to a constant-current stimulus isolation unit (A360, WPI), which was controlled by brief $(100 \mu \mathrm{s})$ digital pulses generated by the ITC-18 computer interface.

Computer simulations of EPSP summation. Computational simulations of EPSP summation were performed using custom programs written in Python that added multiple copies of scaled template EPSP responses. Simulated EPSP timing was based on a set of MC and TC discharges evoked by glomerular layer stimulation and was recorded under cell-attached conditions so as not to perturb the intracellular environment of the recorded neuron. To simulate the synaptic input from one MC or TC, we (1) randomly selected a previously recorded discharge from that cell class corresponding approximately to one respiratory cycle (spikes $300 \mathrm{~ms}$ beyond the stimulus were ignored); (2) processed each spike within the train to determine whether that MC/TC AP would trigger a GC EPSP, based on the measured release probability at that synapse type; (3) if the spike triggered an EPSP, we introduced an onset latency based on a randomly selected DD EPSP latency $(<3 \mathrm{~ms})$ plus an additional latency to represent variable onset of MC discharges. This added latency enables us to determine the effects of nonsynchronous MC ensembles (see Fig. 7D); (4) for the first AP in an MC/TC response, we randomly selected an EPSP amplitude from a library of 335 previously recorded GC EPSPs (excluding failures) assembled from the seven dual WC paired recordings and scaled the template EPSP waveform to that peak amplitude. For subsequent MC/TC APs, the EPSP amplitude selected for the initial EPSP in the train was further scaled by the short-term plasticity at that synapse type using the frequency-composite estimates presented in Figure 3, D and G. We continued to use the short-term plasticity recorded for the fourth AP for the fifth and for subsequent MC/TC APs in the train. This process was repeated to represent a specified number of presynaptic neurons. For example, to simulate the input from five presynaptic neurons, we added scaled and latency-jittered EPSP templates driven by five randomly selected MC spike trains.

Once all the requested presynaptic inputs had be combined, we determined whether the resulting membrane potential $\left(V_{\mathrm{m}}\right)$ would be expected to trigger at least a spike. Since GC APs are typically preceded by a large- amplitude $(>10 \mathrm{mV})$ slow-ramp-up potential before the apparent threshold crossing (estimated AP threshold, $-28.0 \pm 2.8 \mathrm{mV}$ ), we determined the most depolarized stable membrane potential in GCs based on a series of graded current steps $(-42.0 \pm 2.5 \mathrm{mV} ; N=6 \mathrm{GCs})$. In our computer model, simulated membrane potentials more depolarized than this voltage were assumed to trigger spikes. To simulate cortical inputs, we generated short $\gamma$-frequency tonic discharges of APs [5 APs at $40 \mathrm{~Hz}$; interval coefficient of variation $(\mathrm{CV})=0.05$; onset latency jitter $=$ $5 \mathrm{~ms}$, reflecting the propensity of many piriform cortical cells to discharge in $\gamma$-frequency bursts in response to odor stimulation (Zhan and Luo, 2010; Miura et al., 2012). We provided confidence limits on our estimates of the number of presynaptic inputs required to trigger GC spiking by repeating the model 50 times.

Since the modeling approach we used did not incorporate active GC conductances (we simply added EPSP waveforms into an initially constant $V_{\mathrm{m}}$ buffer), these simulations did not reflect the expected decrement in EPSP amplitude because EPSP summation depolarized the GC closer to the EPSP reversal potential. Including this effect would further reduce the already low effectiveness we find in DD EPSPs to trigger GC APs. In some GCs, this effect is often partially offset by the recruitment of additional inward current through NMDA receptors activated at membrane potentials near the threshold. We elected not to include this effect, or to model the interaction of subthreshold EPSPs with intrinsic GC currents, because our pilot experiments attempting to dissect these components revealed a large degree of heterogeneity among GCs. On average, though, depolarizing the membrane potential from -70 to $-55 \mathrm{mV}$ slightly decreased the mean DD EPSP amplitude (to $93.8 \pm 22.7 \%$ of the EPSP amplitude recorded at $-70 \mathrm{mV} ; N=4$ pairs), suggesting that our simulations may underestimate the actual number of presynaptic MCs/ TCs required to trigger a GC AP through the DD synaptic pathway.

Experimental design and statistical analysis. Paired recordings were evaluated for potential monosynaptic connections by averaging 15-30 consecutive GC responses to precisely timed MC discharges (typically, 4 spikes at $40 \mathrm{~Hz}$ ). Pairs in which the average GC response showed an EPSP-like waveform that began 1-3 ms after the MC AP onset were considered potentially connected neurons. Potential connections were further evaluated by examining individual responses and accepted if we observed at least 10 obvious EPSPs driven by the MC AP within a standard monosynaptic latency window (1-3 ms for the onset of presynaptic AP). We never observed potential polysynaptic responses (EPSP-like responses in the average response with latencies $>3 \mathrm{~ms}$ ) consistent with the absence of extensive recurrent excitatory synapses in the OB. Estimates of EPSP amplitude were computed both by manually moving computer cursors in an off-line display program and also by using an automated procedure that calculated the $\Delta V_{\mathrm{m}}$ between the $2 \mathrm{~ms}$ baseline period before the MC $\mathrm{AP}$ and a $0.5 \mathrm{~ms}$ window centered at the peak of the average EPSP response. A similar automated procedure estimated membrane potential noise by calculating the same $\Delta V_{\mathrm{m}}$ measurement at randomly selected time points in the same traces. Bootstrap time windows that occurred within $50 \mathrm{~ms}$ of a spontaneous EPSP were excluded. We report both unitary EPSP amplitudes estimated by manual cursor measurements and the automated bootstrap method (with success indicated by responses more than the mean $\pm 1 \mathrm{SD}$ of the random $\Delta V_{\mathrm{m}}$ measurements) in the text; there was no statistically difference in these measures of unitary EPSP amplitude or between manual and automated estimates of DD release probability. Summary results are presented as mean \pm SEM except for the computation simulation results, which are presented as the mean \pm SD. Statistical comparisons used Student's $t$ test unless otherwise indicated and were performed in Python (version 3.6), using the SciPy. Stats library, and Origin 2017 (OriginLab). Before performing statistical comparisons with $t$ tests, we tested for normal distributions of data points using the Shapiro-Wilk assay implemented in Origin.

\section{Results}

\section{Mitral cell-to-granule cell EPSPs}

This report is based primarily on results from 10 monosynaptically coupled MC/GC pairs obtained from 355 dual MC/GC recordings. Seven of these recordings were based on dual whole-cell 

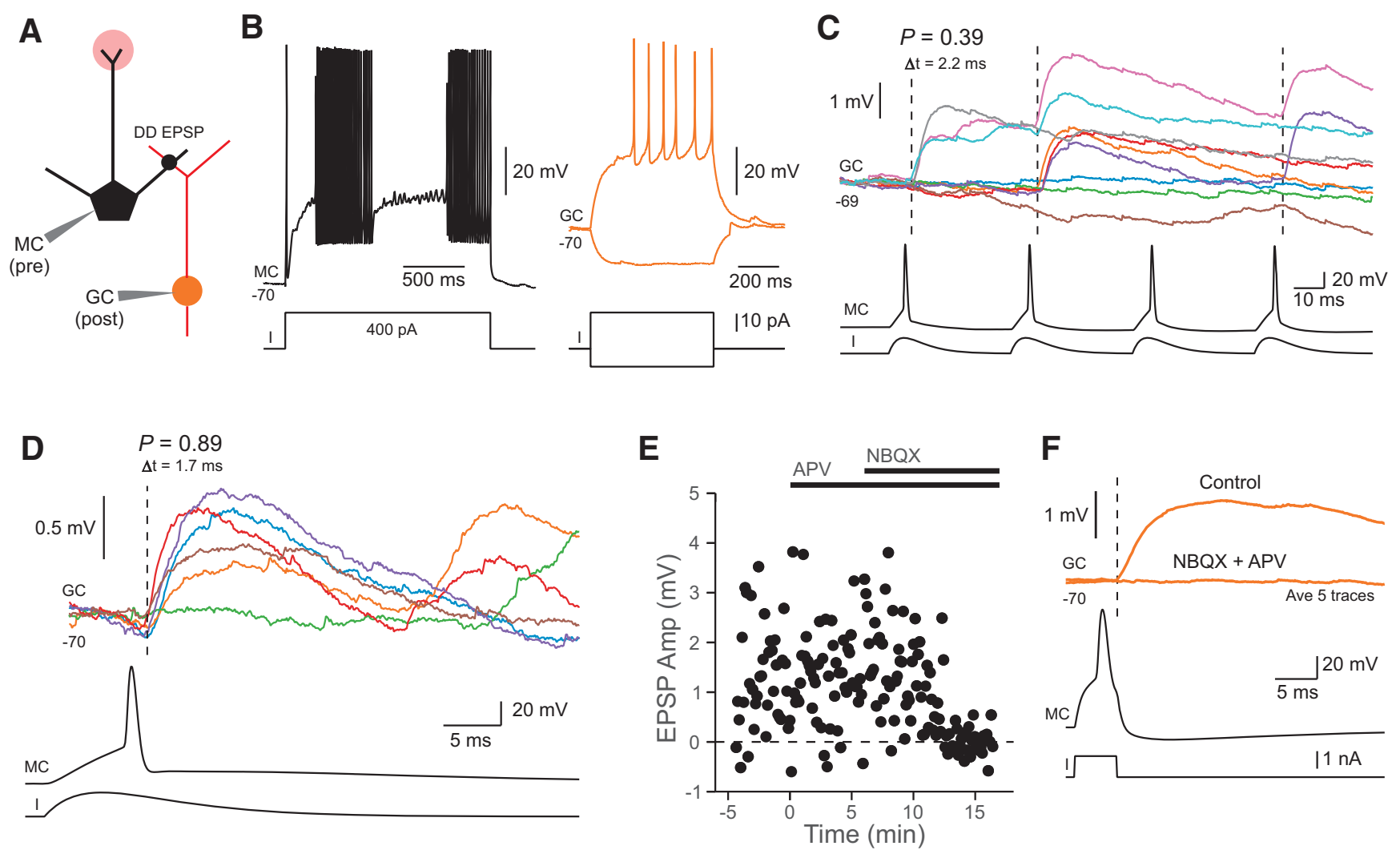

Figure 1. Unitary dendrodendritic EPSPs. $\boldsymbol{A}$, Diagram of dual WC recording configuration. $\boldsymbol{B}$, Responses of the MC (left) and GC (right) to current step stimuli. $\boldsymbol{C}$, Monosynaptic dendrodendritic EPSPs (DD EPSPs) evoked by MC APs. The presynaptic MC and postsynaptic GC are the same neurons shown in $\boldsymbol{B}$. Vertical dashed lines aligned to EPSP onset (mean onset latency, $2.2 \mathrm{~ms}$; overlay of nine traces from one paired recording). Synaptic event probabilities indicated in figure (" $\mathrm{P}$ ") are computed from a larger set of traces than presented in panels. MC AP triggered by repeated alpha function injected current waveforms ( $950 \mathrm{pA}$ peak amplitude). Colored traces represent $\mathrm{GC}$ responses during nine different trials with the same evoked MC firing pattern. D, Monosynaptic DD EPSP responses in a different dual WC MC/GC paired recording. MC APs evoked by repeated alpha function injected waveforms (450 pA peak amplitude). $\boldsymbol{E}$, Plot of the blockade of DD EPSPs responses in a MC/GC paired recording shown in $\boldsymbol{D}$ by glutamate receptor antagonists D-APV $(50 \mu \mathrm{M})$, followed by D-APV in combination with in NBQX (5 $\mu \mathrm{m})$. Horizontal bars indicate the timing of receptor antagonist bath application. $\boldsymbol{F}$, Example average responses from monsynaptic MC/GC paired recordings shown in $\boldsymbol{D}$ and $\boldsymbol{E}$ under control conditions and in NBQX $+D-A P V$.

recordings (from 255 experiments; $2.75 \%$ connection probability), which enabled visualizing the presumptive synaptic apposition between the two cells using live two-photon imaging. We found only one presumptive contact between the two synaptically coupled cells in each of these 7 experiments (6/7 were dendrodendritic and one was soma-dendritic). Since we can exclude axo-dendritic synapses in the seven connected dual WC recordings, we refer to the evoked GC synaptic responses as "dendrodendritic" EPSPs, which is consistent with the large number of studies in the literature on anatomical and functional connections (Rall et al., 1966; Isaacson and Strowbridge, 1998; Schoppa et al., 1998; Balu et al., 2007), even though one connection appears to be soma-dendritic. The other three connections included in this study resulted from WC recordings from GCs combined with LP recording from MCs (from 100 paired MC/GC recording experiments; $3 \%$ connection probability). The LP recordings used a custom-built amplifier that enabled both stimulation and recording of MC APs (Fig. 2; for details, see Materials and Methods; Strowbridge and Pressler, 2017). The properties of these three GC EPSPs were similar to the seven connections found using dual WC recordings. We therefore included these results in most statistical analyses of DD EPSPs although we identify which data points are from dual WC and LP/WC recording in the illustrations.

Dendrodendritic synapses from MCs to GCs generate highly variable, depressing synapses onto GCs. Figure $1 A-C$ illustrates an example of one of the seven dual WC recordings where $\mathrm{MC}$ APs evoked EPSPs in GC. Both MC and GC recordings were performed under current clamp, enabling us to assess both GC maturity and to test responses to physiological AP stimuli in the presynaptic MC cell. As reported previously (Desmaisons et al., 1999; Balu et al., 2004; Balu and Strowbridge, 2007), MCs responded to depolarizing current steps with intermittent clusters of APs when held near $-70 \mathrm{mV}$ (Fig. 1B, left). All seven visualized postsynaptic GCs in this report had extensive apical dendritic branches with numerous gemmules in the external plexiform layer (EPL). All 10 postsynaptic GCs appeared to be mature (at least stage 5) based on established electrophysiological criteria (e.g., ability to fire repetitive, large-amplitude APs; Fig. $1 B$, right; $>3.5 \mathrm{~Hz}$ spontaneous EPSP frequency; Carleton et al., 2003; Fig. 2C, below).

Both the release probability and the unitary amplitude of MCevoked EPSPs were strikingly variable among the 10 connected MC/GC pairs we identified. In the example shown in Figure 1C, release probability is relatively low $(p=0.39)$ with more responses to the second MC AP than the first AP. Yet, another MC/GC paired recording — also appearing to be a dendrodendritic synaptic connection based on two-photon visualization of the sole apposition between the filled neurons-had very few response failures and a high response probability ( $p=0.89$; Fig. $1 D$ ). In three connected pairs, we were able to determine the effects of ionotropic glutamate receptor blockers (NBQX and APV). This combination of receptor antagonists completely abolished postsynaptic responses in GC to 

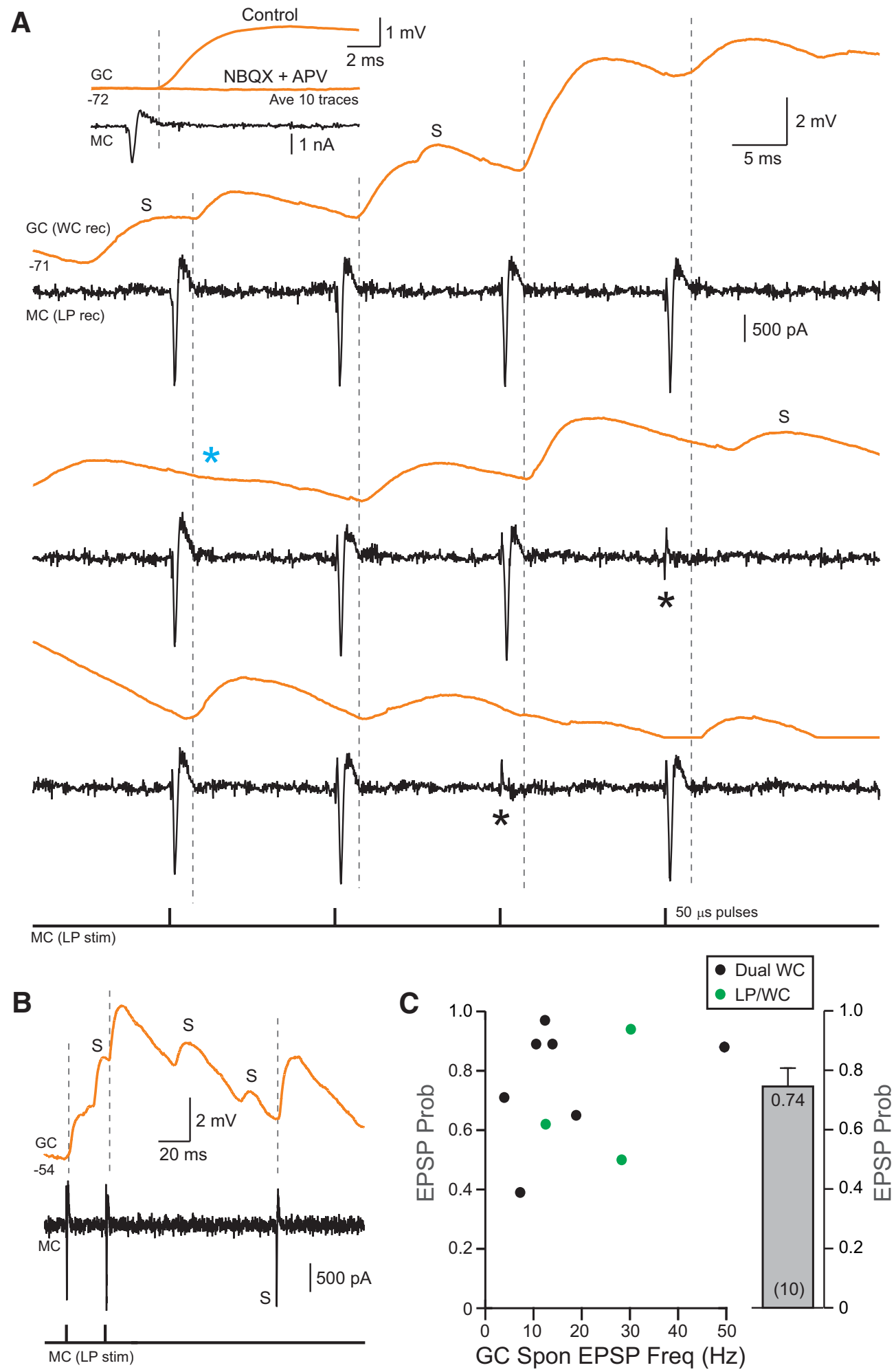

Figure 2. Dendrodendritic EPSPs recorded (rec) in using dual WC amplifiers and using loose-patch stimulation. A, GC EPSPs evoked by MC spikes recorded through a custom loose patch-clamp amplifier (for details, see Materials and Methods). MC APs evoked by brief (50 $\mu$ s duration) depolarizing voltage stimuli. The same amplifier was used to stimulate and record MC APs in all three sweeps; MC responses are shown with the stimulus artifact subtracted. Black asterisks indicate MC stimuli that failed to trigger an AP; the blue asterisk indicates GC EPSP failure. Spontaneous GC EPSPs are indicated by "s." Inset shows the blockade of MC-evoked EPSP by NBQX + APV. Each response represents an average (Ave) of 10 trials. B, Similar GC EPSPs in response to triggered and spontaneous MC APs. A spontaneous MC AP is indicated by "s." C, Plot of DD release probability versus spontaneous EPSP frequency in postsynaptic GCs ( $r=0.25$; black symbols from dual WC paired recordings; green symbols from LP MC recording combined with WC GC recording). Bar plot (right) summarizes the DD release probability for 10 DD paired recordings.

MC APs in all three experiments (Figs. $1 E, F, 2 A$, inset below). As shown in the scatter plot of postsynaptic response amplitude (Fig. $1 E)$, MC-evoked EPSP amplitudes often were highly variablereflecting properties that are defined quantitatively below.
In 3 of the 10 connected MC/GC pairs, the presynaptic neuron was recorded using a custom-built patch-clamp amplifier that enabled voltage steps large enough to trigger MC APs under the loose patch-clamp recording configuration (Barbour and Isope, 
2000; Strowbridge and Pressler, 2017). Figure 2 illustrates example presynaptic and postsynaptic responses evoked by very brief (50 $\mu$ s duration) depolarizing pulses applied to membrane patches from MC somata. Despite using a relatively simple amplifier design, APs evoked by brief depolarizing pulses could easily be differentiated from subthreshold MC responses [Fig. 2A, black traces (showing three sweeps at perithreshold stimulus intensity for the MC)].

Unitary GC responses evoked through presynaptic LP recordings (Fig. $2 A, B$ ) closely resembled postsynaptic responses evoked in conventional dual WC recordings in terms of unitary amplitude and variability and also were abolished by the presence of ionotropic glutamate receptor antagonists (Fig. $2 A$, inset). Because the steady-state membrane potential cannot be controlled in LP recording as it can with conventional current-clamp WC recordings, we occasionally observed spontaneous APs in presynaptic MCs. Those spontaneous MC APs also generated EPSPs in postsynaptic GCs (Fig. 2B; spontaneous MC spiking was frequent in only one-third of presynaptic MCs recorded with the LP amplifier). While LP recording precludes visualization of the presynaptic neuron, the number of MC/GC pairs that could be tested for synaptic connections per day was higher (typically by three to four times) primarily because the same LP pipette could be used to record from multiple MCs. The higher throughput of LP/WC paired recordings makes this technique especially advantageous for identifying sparse synaptic connections, such as DD synapses in the $\mathrm{OB}$.

As shown in Figure $2 C$, release probability at DD excitatory synapses varied from 0.4 to almost 1 (mean, 0.74) and was not correlated with the frequency of spontaneous EPSPs in the postsynaptic GC, another indicator of GC age (Carleton et al., 2003; Whitman and Greer, 2007). We observed a similarly large range of release probabilities in both dual WC (Fig. 2C, black symbols) and LP/WC recordings (Fig. 2C, green symbols). While these estimates of release probability were based on visual inspection of each trace, we found similar probabilities $(0.77 \pm 0.08 ; N=7$ dual WC recordings) using an automated bootstrap procedure that determined whether each postsynaptic response was greater than the ongoing noise (see Materials and Methods). While we did not attempt to determine the reversal potential of the DD EPSP in these relatively short-duration paired recordings, hyperpolarizing the membrane potential from -70 to $-90 \mathrm{mV}$ increased the average EPSP amplitude by $21.8 \%$ ( $N=5$ pairs $)$, as expected for ionotropic glutamate receptor-mediated synaptic responses (Jonas et al., 1993) for excitatory inputs onto hippocampal CA3 pyramidal cells). We assayed the effect of blocking only NMDA receptors with APV alone in all three cells but found variable results (Fig. 1E, peak average amplitude unaffected in two-thirds of cells, including the example responses plotted in, and slightly decreased in the third GC). Previous studies of presumptive DD EPSPs and DD-mediated self-inhibition of MCs (Isaacson and Strowbridge, 1998; Schoppa et al., 1998; Isaacson, 2001) found that NMDA receptors preferentially triggered GABA release from GCs, suggesting the depolarizing voltage-clamped MCs can potentially trigger GC EPSPs with a large NMDA receptormediated component. The absence of a large NMDA receptor component in our small sample of DD paired recordings may reflect inadequate dendritic depolarization (we tested APV sensitivity with the somatic membrane potential set to approximately $-55 \mathrm{mV}$ ), a requirement for the activation of multiple DD inputs and/or heterogeneity among DD EPSPs. We tested for a reverse DD connection in three pairs by triggering GC APs and failed to observe any $\mathrm{MC}$ responses. Our recording conditions, however, were not optimized to record low-amplitude inhibitory re- sponses, and all of the visualized appositions in the pairs tested for reverse connections were relatively distant (approximately one electrotonic length constant; Lowe, 2002) from the MC somata.

\section{Comparison with other synaptic inputs onto GCs}

We next defined the short-term plasticity present in excitatory DD synapses onto GCs using short trains of four to six MC APs evoked at different intervals that span most of the physiological firing frequency range of MCs (Fig. 3A-D). Mitral cell discharges are typically within the $\gamma$-frequency band and can reach frequencies of $>70 \mathrm{~Hz}$ (Balu et al., 2004; Cury and Uchida, 2010; Shusterman et al., 2011). Triggering of APs using periodic injection of current waveforms (either pulses or $\alpha$ functions) becomes less reliable at higher rates; the fastest trains we attempted were using $15 \mathrm{~ms}$ intervals (generating $67 \mathrm{~Hz}$ firing). With moderate firing frequencies $(40 \mathrm{~Hz})$, DD EPSPs rapidly depressed following the second AP in the train (Fig. $3 B, C$ ). We found this general pattern of decreasing average EPSP amplitude at all four MC firing frequencies tested (Fig. 3D). With low $\gamma$-band MC discharges $(25-40 \mathrm{~Hz})$, there was relatively little depression in response to the second AP. By the fourth AP, however, the mean EPSP amplitude had decreased by at least $50 \%$ at all four MC firing frequencies tested (on average, $30 \%$ of initial response).

While previous work from our group (Balu et al., 2007) found synaptic depression on presumed DD EPSCs evoked from focal extracellular stimulation in the EPL, the present results are, to our knowledge, the first direct recording of the short-term plasticity found in the most prevalent local excitatory synapse in the OB. The synaptic depression we find during trains of four APs continued in a subset of the experiments in which we were able to test responses to longer MC trains. In $40 \mathrm{~Hz}$ trains of MC APs, the fifth and sixth AP generated EPSPs with average amplitudes of $25.4 \%$ and $27.7 \%$ of the initial EPSP ( $N=4$ experiments). The rapid falloff in average GC EPSP amplitude during trains of $\gamma$-band MC APs is counterintuitive because MCs typically generate extended discharges composed of more than eight spikes during natural sensory stimulation (Davison and Katz, 2007, their Fig. 7; Cury and Uchida, 2010, their Fig. 7D). The pronounced and relatively frequency-independent short-term depression at this synapse suggests that GCs are depolarized primarily by the initial few APs in an MC discharge.

The short-term depression we find in DD inputs to GCs contrasts with the facilitating EPSP responses generated by cortical "feedback" inputs that synapse on the proximal dendrites of the same neurons (Fig. 3E-G; de Olmos et al., 1978; Haberly and Price, 1978; Nakashima et al., 1978; Balu et al., 2007). As shown in the example response in Figure $3 E$, the average amplitude of cortical EPSPs evoked by focal, two-photon-guided stimulation near the proximal GC dendrite increased more than twofold in response to the second shock and remain facilitated throughout the train. We examined this pattern of large facilitation in response to the second and third stimulus across the three frequencies $(20-40 \mathrm{~Hz}$; Fig. $3 F, G)$. These results demonstrate that two different types of excitatory synaptic inputs onto GCs have dramatically different forms of short-term plasticity. These divergent results also make it less likely that the short-term depression we find in DD excitatory synapses reflects artifacts associated with the WC postsynaptic recording configuration since GCs were recorded under identical conditions in both sets of experiments.

The differences in short-term plasticity between DD and cortical feedback EPSPs reflect changes in both unitary EPSP amplitude and release probability. As shown in Figure $3 H$, unitary DD EPSP amplitude in response to the initial AP was variable across 
A

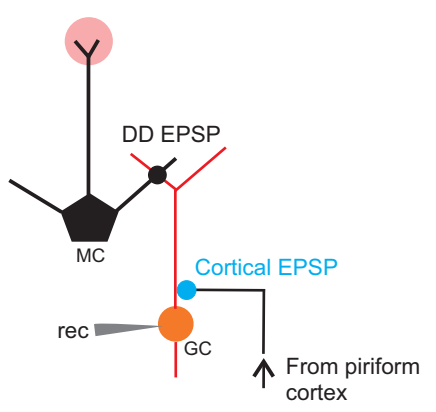

B

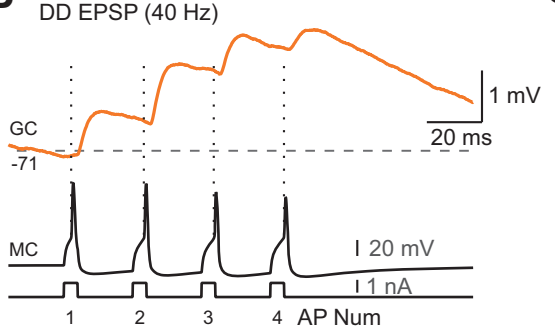

E

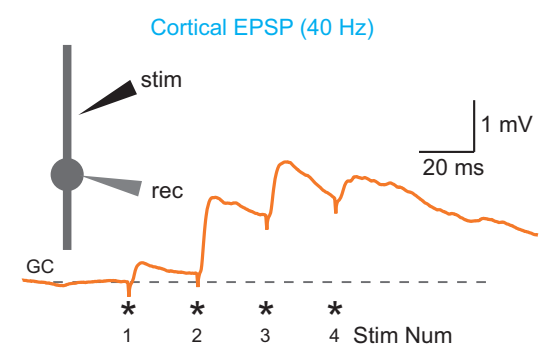

C

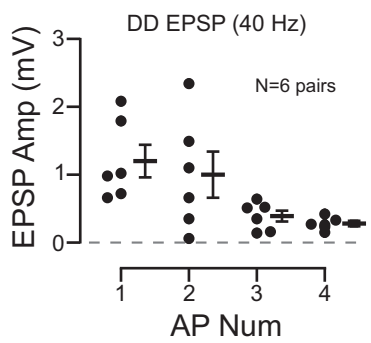

D

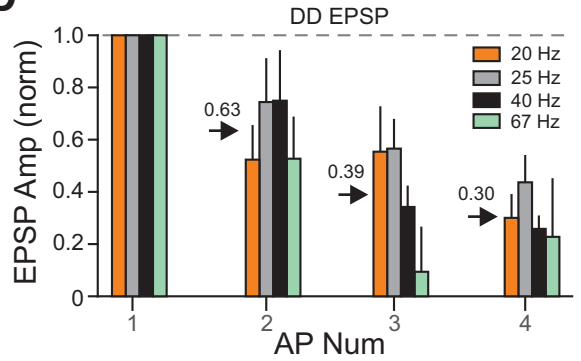

G

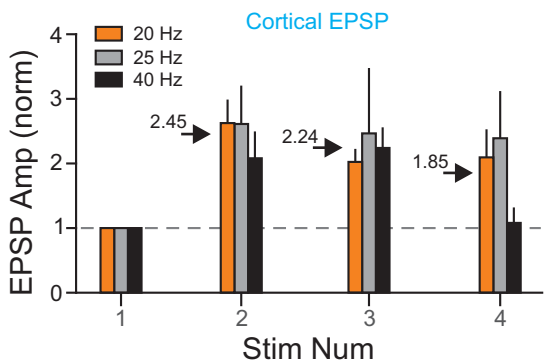

H

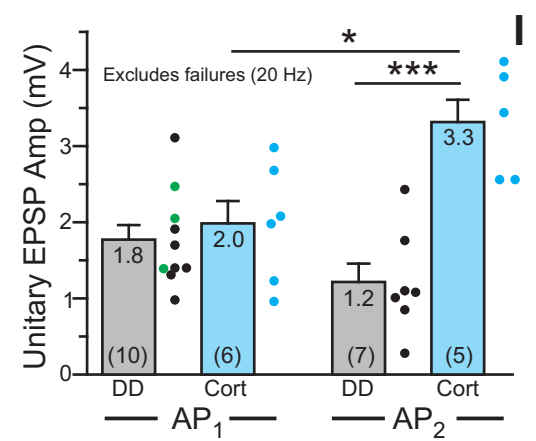

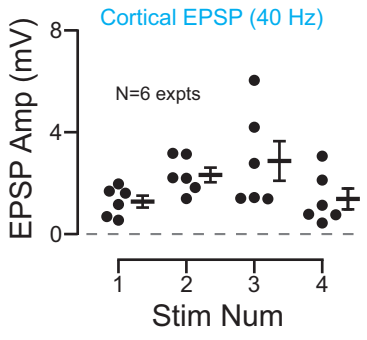

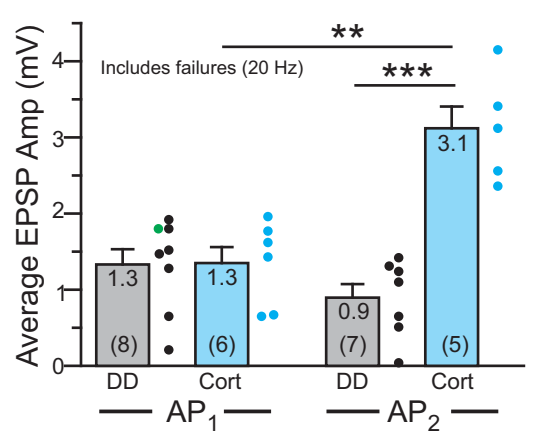

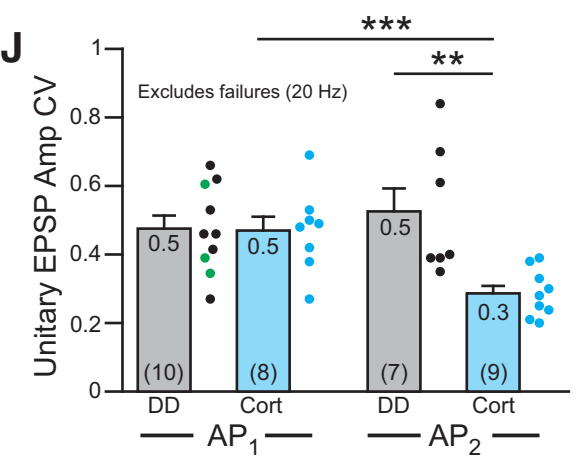

Figure 3. Short-term plasticity of the DD and cortical (Cort) EPSPs onto GCS. A, Diagram of GC recording (rec) configuration. $B$, GC response to trains of MCAPs at $40 \mathrm{~Hz}$. Vertical dashed lines aligned to MC AP onset. Average of 22 trials. C, Summary of results from six dual MC/GC WC recordings, similar to those shown in $\boldsymbol{B}$. Overall mean and SEM presented to the right of mean EPSP amplitude from each experiment. $D$, Summary of short-term plasticity in at the DD EPSP. Results from summary plots similar to $C$ were normalized by setting the mean amplitude of the $\mathrm{GC}$ response to the first AP equal to 1. Colored bars represent different MC firing frequencies (all evoked by trains of current pulses; $N$ values between 3 and 7 experiments for each bar). Horizontal arrows indicate the overall

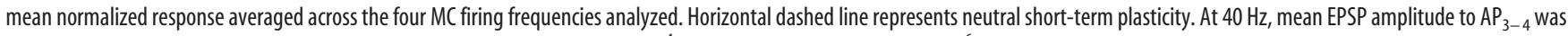
significantly reduced compared with $\mathrm{AP}_{1} . p=0.12$ (not significant), $1.9 \times 10^{-4}(T=-8.47 ; \mathrm{df}=5), 6.0 \times 10^{-6}\left(T=-17.3\right.$, df $=5$ ) for $\mathrm{AP}_{2-4 ;} ; \mathrm{N}=6$ experiments; one-sample $t$ test. $\boldsymbol{E}$, Responses to perithreshold focal stimulation (Stim) at $40 \mathrm{~Hz}$ near the proximal apical dendrite of a different $\mathrm{GC}$ (average of 10 trials). $\boldsymbol{F}$, Summary of six focal two-photon-guided $40 \mathrm{~Hz}$ stimulation experiments similar to those shown in $\boldsymbol{E}$. G, Overall summary of short-term plasticity at cortical EPSPs onto GCs using the same protocol shown in $\boldsymbol{E}$ and $\boldsymbol{F}$. Same notation as for $\boldsymbol{C}$. All bars represent the mean \pm SEM from three to six experiments. At $40 \mathrm{~Hz}$, the mean EPSP amplitude to AP ${ }_{2-3}$ was increased compared with AP. $. p=0.02(T=2.7, \mathrm{df}=5), 0.0047(T=4.1, \mathrm{df}=5), 0.36(\mathrm{not}$ significant) for $\mathrm{AP}_{2-4} ; \mathrm{N}=6$ experiments; one-sample $t$ test. $\boldsymbol{H}$, Plot of unitary EPSP amplitude evoke by trains of two presynaptic MC APs (DD EPSPs; 50 ms interspike interval; black symbols from dual WC pairs; green symbols from LP/WC pairs) and trains of two focal microstimulation pulses applied near the proximal apical dendrite (Cort EPSP; $50 \mathrm{~ms}$ ISI; blue symbols). . $p=0.028$, $T=-2.88$, unpaired $t$ test; ${ }^{* * *} p=4.8 \times 10^{-4}, T=-5.1$, unpaired $t$ test. $I$, Plot of the average EPSP amplitude (from all trials, including failures). ${ }^{* *} p=0.0013, T=4.61$, unpaired $t$ test; ${ }^{* * *} p=8.4 \times 10^{-5}, T=6.34$, unpaired $t$ test. $J$, Plot of the variability in unitary amplitude (amplitude CV) for both DD EPSPs and cortical EPSPs onto GCs. ${ }^{* *} p=0.0036, T=-3.5$, unpaired $t$ test; ${ }^{* * *} p=2.7 \times 10^{-7}, T=-11.0$, unpaired $t$ test. Num, Number. 
A

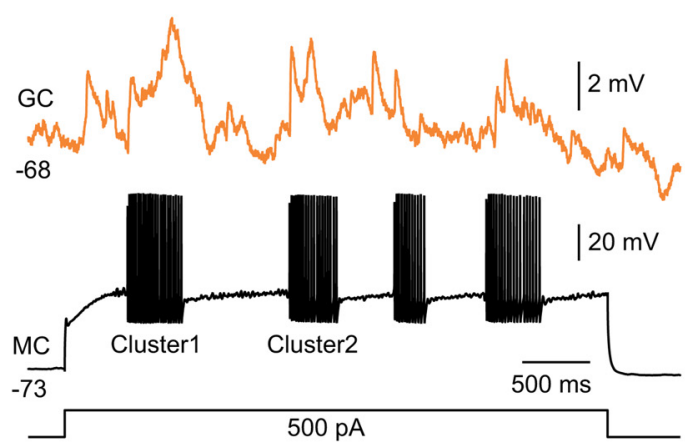

C

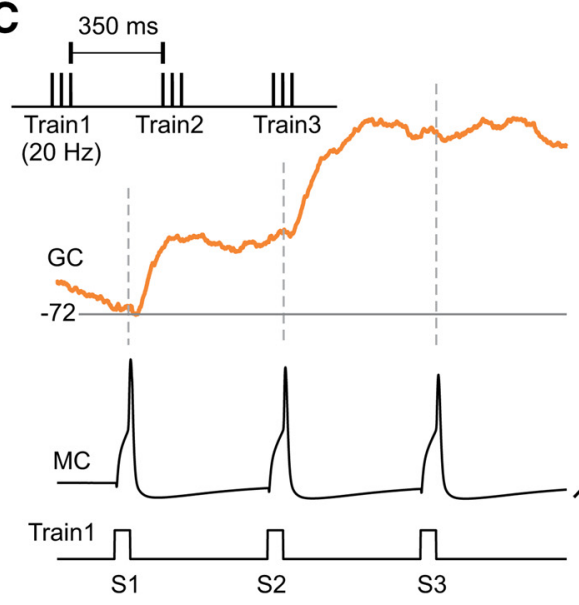

B

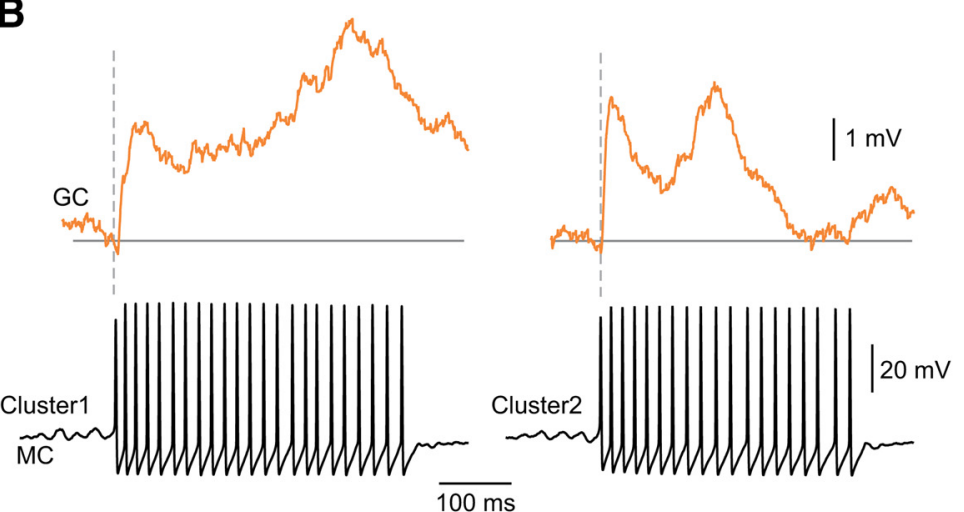

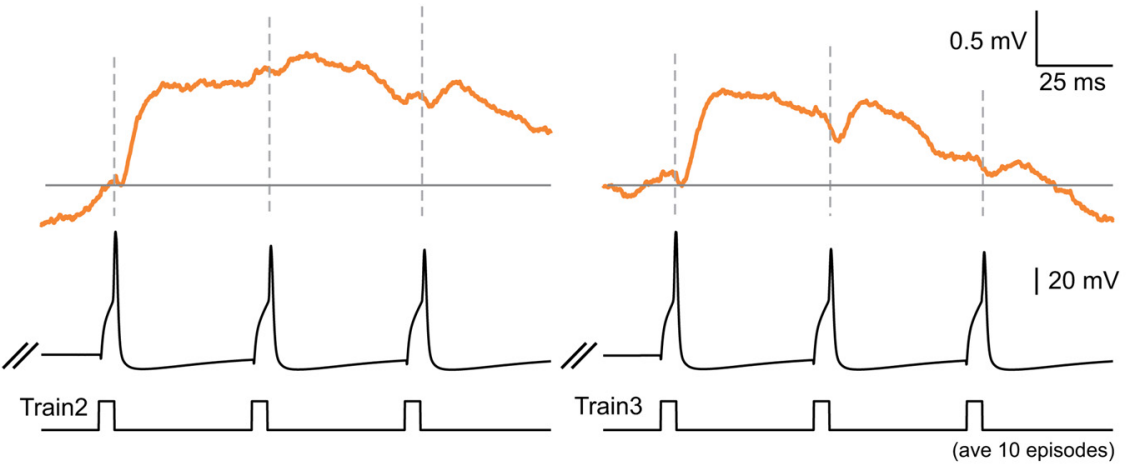

Figure 4. Recovery from short-term depression of DD EPSP. $A$, Response of a $\mathrm{GC}$ to intermittent MC discharges evoked by a $4 \mathrm{~s}$ depolarizing step. $B$, Enlargements of the $\mathrm{GC}$ responses to the first two spontaneous MC clusters shown in $\boldsymbol{A}$. Vertical dashed lines mark the onset of initial AP in each cluster. C, Responses of a GC to patterned MC firing (three bursts of APs at $20 \mathrm{~Hz}$, with a $350 \mathrm{~ms}$ interval between trains; timing schematic diagram indicated in inset). Initial DD EPSP response in each MC AP train recovers during the intertrain interval. Vertical dashed lines indicate the onset timing of MC APs. GC responses are averages of the same 10 trials of the same MC firing pattern. $A-C$ are from the same MC/GC paired recording.

different experiments but was not different from cortical EPSPs. We obtained similar estimates of unitary EPSP amplitude using visual inspection of each episode $(1.77 \pm 0.11 ; N=10$; Fig. $3 H)$ and automated bootstrap analysis $(1.57 \pm 0.18 ; N=10 ; p=0.45$, unpaired $t$ test). The cortical EPSPs evoked by the second AP within a $20 \mathrm{~Hz}$ train were approximately threefold larger than the DD EPSPs evoked by a similar stimulus train. The small decrease in average DD amplitude in responses to the second MC AP primarily reflected a small decrease in unitary EPSP amplitude (33\% decrease at $20 \mathrm{~Hz} ; 2 \%$ decrease at $40 \mathrm{~Hz}$; neither decrease was statistically significant) since release probability was similar in response to both APs. We found a similar pattern when analyzing mean EPSP amplitude (averaging all trials) in these experiments (Fig. 3I) with relatively similar initial DD and cortical EPSPs but divergent second EPSPs (modestly depressing in DD synapses and strongly facilitating in cortical EPSP inputs). These results suggest that divergent forms of short-term synaptic plasticity are likely to be more useful in differentiating DD and cortical GC EPSPs than responses to the initial presynaptic spikes, which were remarkably similar at both proximal and distal inputs to GCs. In addition to divergent forms of short-term plasticity, unitary EPSP responses evoked by the second AP were much less variable in cortical synapses than DD inputs (Fig. $3 J$ ). The small average EPSP amplitude, striking short-term depression across all frequencies tested and large trial-to-trial variability in response amplitude suggest that $\mathrm{DD}$ synapses by themselves are unlikely to trigger frequent GC spikes in vivo. Instead, these properties suggest that DD synapses function to minimize the ability of repeti- tive discharges in any one presynaptic $\mathrm{MC}$ from depolarizing postsynaptic GCs to threshold.

Mitral cells respond to sustained depolarizing steps with intermittent clusters of APs with the average interval between clusters similar to the natural basal respiration rate $(\sim 2-3 \mathrm{~Hz}$; Margrie and Schaefer, 2003; Balu et al., 2004; Balu and Strowbridge, 2007; Cury and Uchida, 2010; Shusterman et al., 2011). In three MC/GC paired recordings, we were able to assess postsynaptic EPSP responses during presynaptic AP MC clusters (Fig. $4 A, B)$. In all three pairs, only the initial one to two MC APs within a cluster reliably triggered EPSPs in the GC (Fig. $4 B$, example recordings), suggesting that the degree of short-term plasticity we report (Fig. 3) likely underestimates the naturally occurring degree of synaptic depression present during long-duration, rapid MC discharges. (The initial firing rate within MC AP clusters evoked by sustained depolarizing steps, $70-80 \mathrm{~Hz}$ in the example $\mathrm{MC}$ in Fig. $4, A, B$, is faster than we can reliably trigger using discrete current waveforms.) In all three MC/GC pairs tested, the spontaneously occurring pauses in MC firing during sustained depolarizing steps $(555 \pm 60 \mathrm{~ms}$ in the presynaptic MCs in our dataset) were long enough to reverse the short-term depression and enable the initial MCAP in the next cluster to trigger an EPSP (initial EPSP amplitude in second and subsequent AP clusters was $100 \pm 23 \%$ of the amplitude of initial EPSP in the first cluster; $N=6$ ). We were able to study the recovery from synaptic depression using precisely timed MC AP sequences in one dual WC paired recording and found no depression in the response to the initial AP within an MC spike cluster (normalized EPSP ampli- 

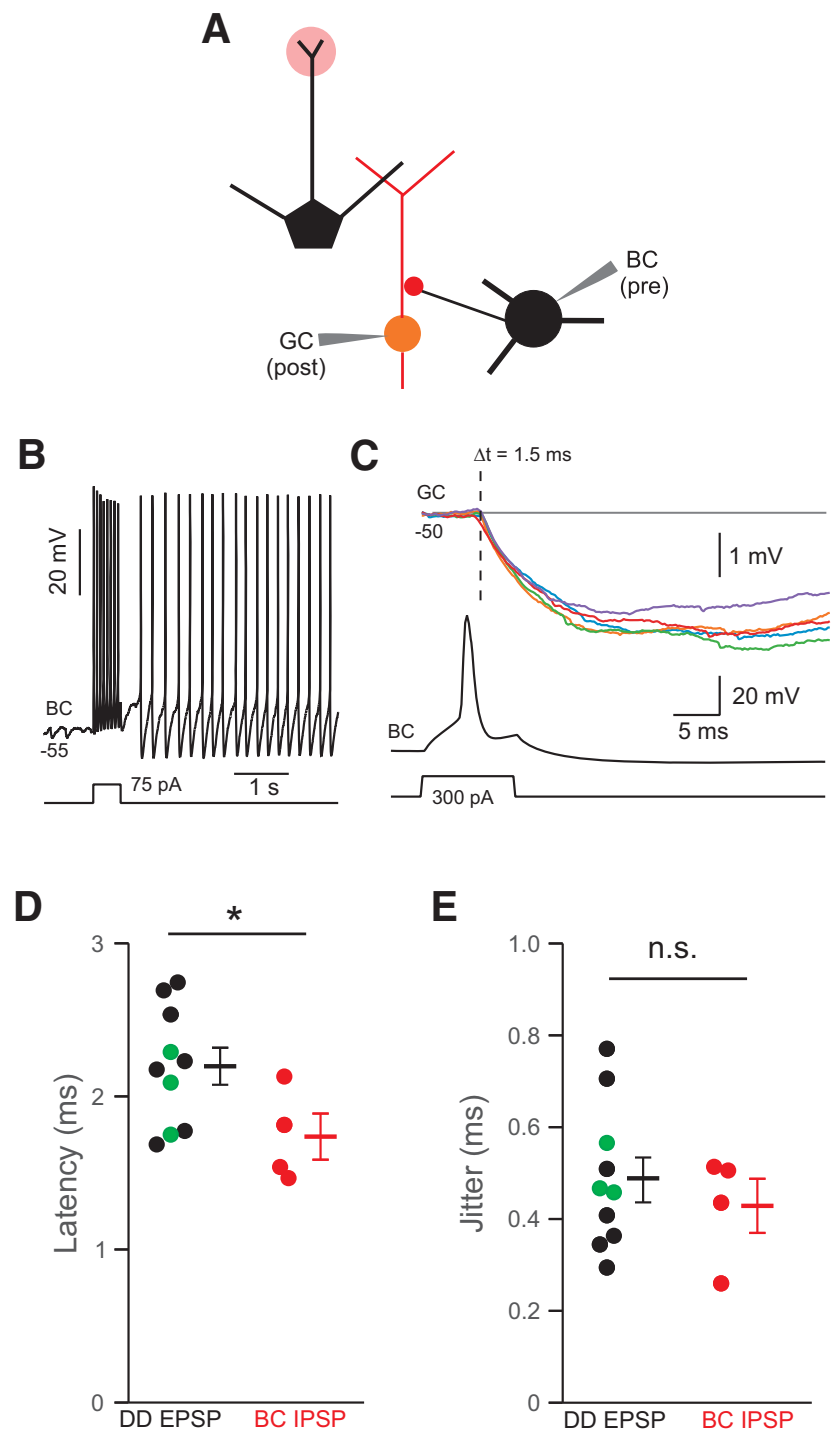

Figure 5. Comparison of DD EPSP and Blanes cell-mediated IPSPs onto GCS. A, Diagram of dual WC recording configuration. $\boldsymbol{B}$, Persistent firing evoked by a brief $(500 \mathrm{~ms})$ depolarizing current step in a BC. C, IPSPs evoked by single APs in the BC shown in $\boldsymbol{B}$ and recorded in a monosynaptically coupled $G C$. Colored traces represent five responses to the same $B C$ spike. $D$, Summary of onset latency to DD EPSPs and BC-mediated IPSPs in GCs. Black symbols represent the results from dual WCMC/GC paired recordings. Green symbols represent $M C / G C$ paired recordings where the $M C$ was stimulated through a loose patch-clamp amplifier. ${ }^{*} p=0.027$, $T=2.1, \mathrm{df}=12$, unpaired $t$ test. $\boldsymbol{E}$, Summary of EPSP/IPSP latency jitter (SD of onset latency). Same symbols as in $\boldsymbol{D}$. $p=0.25$ (n.s.), unpaired $t$ test.

tudes, 1:1.24:1.22; Fig. 4C; AP clusters repeated at 2.9 Hz). These results suggest that pronounced short-term depression associated with DD excitatory synapses is likely "reset" in the interval between inhalations, at least during basal respiration.

In addition to the cortical feedback EPSP, the only other fast (nonmodulatory) synaptic input onto GCs that has been defined through paired intracellular recordings is the GABAergic input from Blanes cells (BCs; Pressler and Strowbridge, 2006), large multipolar interneurons that also reside within the GCL (Ramon y Cajal, 1911; Eyre et al., 2008, 2009). Blanes cells are distinctive because of their robust ability to fire persistently in response to brief depolarizing stimuli under physiological ACSF conditions (Fig. 5A,B). Like many DD EPSP connections we found, BC IPSPs have high release probability ( $93 \%, N=4$ experiments; Pressler and Strowbridge, 2006). The latency of BC IPSPs is sig- nificantly shorter than DD EPSPs (Fig. 5D). In many cortical regions, synaptic responses evoked by inhibitory interneurons have shorter latencies than EPSPs onto the same postsynaptic neuron (Miles and Wong, 1984, 1986). In this way, the OB appears to follow similar synaptic timing principles found in other CNS regions despite the different type of presynaptic element (axon terminals for BC IPSPs and secondary dendrites for DD EPSPs). Synaptic response jitter was similar in BC IPSPs and DD EPSPs (Fig. $5 E$ ), as was the variability of unitary BC IPSP amplitudes $(\mathrm{CV}=0.43 \pm 0.05 ; N=4)$ and DD EPSPs $(0.48 \pm 0.04$; $N=10 ; p>0.05$, unpaired $t$ test). The similarity in these synaptic properties provides further evidence that in terms of basic synaptic properties, presynaptic MC dendrites appear to be similar to more thoroughly studied axonal terminals.

\section{Morphological properties of presumptive dendrodendritic synaptic contacts}

In all seven synaptically connected dual WC paired recordings, we identified a single apposition following reconstruction of twophoton image $z$-stacks. Six of the seven appositions were between the a secondary dendrite of the MC between 45 and $74 \mu \mathrm{m}$ from the somata and the GC apical dendrite. In the seventh experiment, the apposition was formed between the MC somata and a spine off of a tertiary branch of the GC apical dendrite. Since all identified appositions were located at relatively proximal sites along the MC dendritic tree, the complete $z$-reconstructions, such as in Figure 6A, are complex and include many (typically $>8$ ) dendritic processes that travel through the relevant region of the EPL. We confirmed putative appositions both in highermagnification $z$-stacks (Fig. $6 B$ ) and by examining short sequences of consecutive individual frames (Fig. $6 C$ ). In the experiment shown in Figure 6, the only two filled neurons in the brain slice were from the synaptically coupled neuron pair, enabling us to unambiguously attribute thin spiny dendritic segments to the postsynaptic GC. As shown in example reconstructions in Figure 6, B and $C$, the spine head at the presumptive apposition was approximately the same diameter as other nearby spine heads associated with the same GC. In the postsynaptic GC shown in Figure $6 B$, the spine head associated with the MC apposition was $77 \%$ of the mean area estimated from 18 nearby spines contained within the same $z$-stack reconstruction. Over a set of five GC reconstructions from connected MC/GC pairs, the area of the spine head associated with the MC apposition was $85.1 \pm 8.2 \%$ of the area of nearby spine heads contained within the same $z$-stack montage (three of five appositions were slightly smaller than the mean area, while two of five appositions were slightly larger than the mean area). Technical issues precluded quantifying the relationship between the spine associated with the MC apposition and nearby spines on the same GC in two of seven dual WC recordings (e.g., overlapping MC processes).

Aside from the somatic MC synapse, the appositions associated with most of the DD EPSPs were clustered at $\sim 70 \mu \mathrm{m}$ from the MC cell body (Fig. 6D). We attempted to maintain the same type of recording configuration in all paired recordings, selecting MCs and GCs that were approximately "on-beam" with each other (i.e., along the same axis perpendicular to the mitral cell layer). The absence of more proximal DD synapses may reflect a lower density of MC/GC synapses at the very proximal part of MC secondary dendrites, as suggested by previous anatomical studies (Bartel et al., 2015). We found no correlation between the unitary EPSP amplitude (the amplitude of the successes) and the distance of the apposition from the GC cell body $(r=0.08$; Fig. $6 E)$. While our sample size was limited in this study, this finding suggests that DD EPSP amplitude is unlikely 

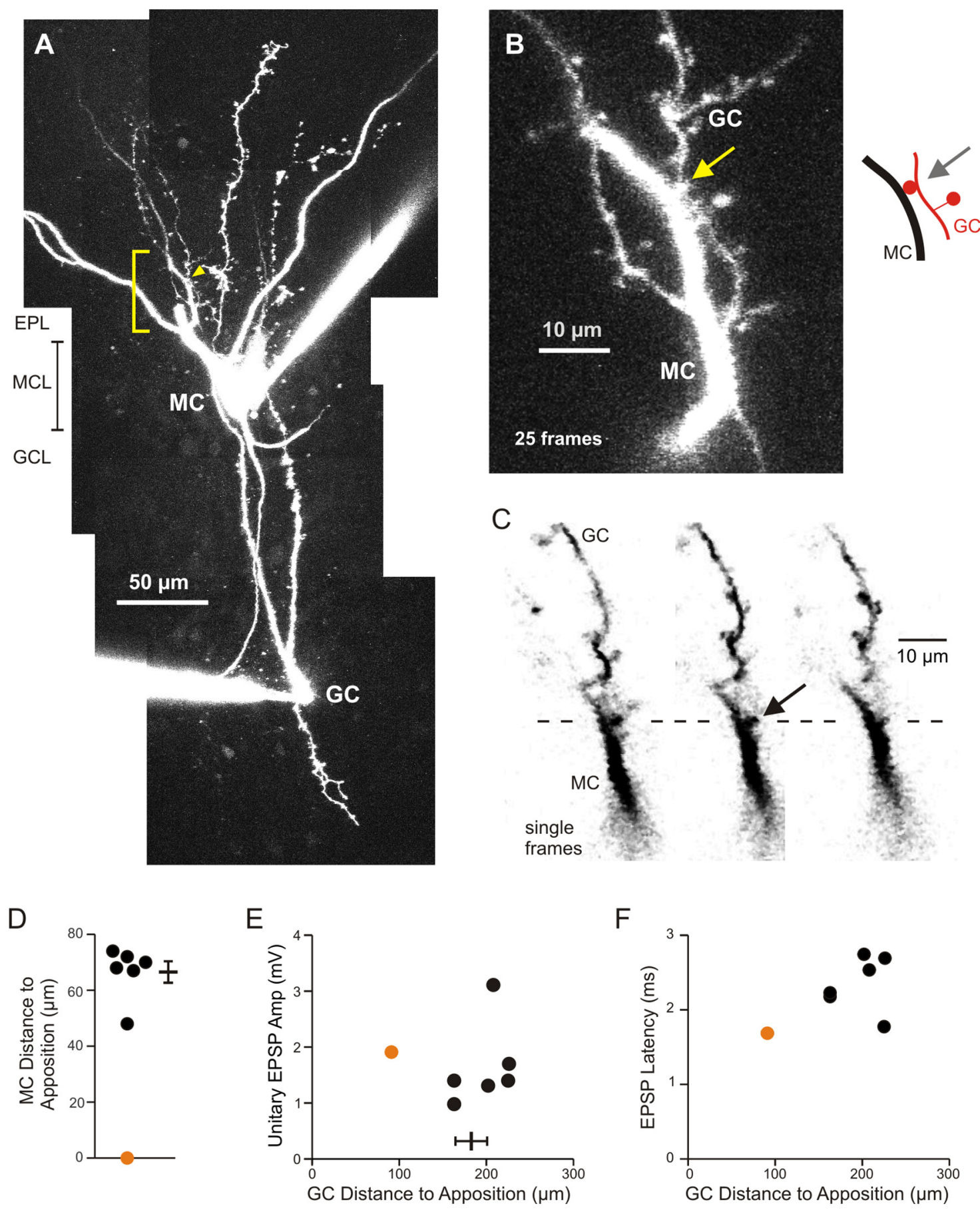

Figure 6. Visualization of $M C / G C$ apposition in synaptically coupled paired recordings. $A$, Montage from six two-photon $z$-stacks of the mitral and granule cells in the paired recording shown in Figure $1 F$. Yellow arrowhead indicates site of dendrodendritic apposition. Yellow bracket indicates the enlargement shown in $\boldsymbol{B}$. The primary apical dendrite of the $\mathrm{MC}$ was truncated during slice preparation. Only one MC and GC were filled with Alexa Fluor 594 in this brain slice. $\boldsymbol{B}$, Enlargement of the area containing the MC/GC dendritic apposition (yellow arrow). Image from a different $z$-stack than that used in $\boldsymbol{A}$ and excludes several frames that included additional MC dendrites (that overlapped regions near the apposition but at a different $z$-level) for clarity. Diagram of apposition region shown at left. The GC spine neck is below the spine head (and is not visible in this z-stack) because the connected dendritic segment dipped slightly near the apposition. $C$, Three individual consecutive single frames of the apposition region (black arrow). Horizontal dashed reference line is at the same location within each frame. Reversed color scale. $\boldsymbol{D}$, Plot of the distance from the synaptic apposition to the MC somata in the seven dual WC connected pairs. Orange symbol in $\boldsymbol{D}-\boldsymbol{F}$ represents the one somata- dendrite apposition. Mean distance \pm SEM of the six dendrodendritic appositions shown on the right. $\boldsymbol{E}$, Plot of the distance from the apposition to the GC somata versus unitary EPSP amplitude. $r=0.08$ (not statistically significant, $p>0.05$ ). $\boldsymbol{F}$, Plot of the distance to the $\mathrm{GC}$ somata versus EPSP latency. $r=0.57$ (not statistically significant, $p>0.05$ ).

to be strongly influenced by variable degrees of electrotonic attenuation. Similarly, both EPSP latency (Fig. $6 F$ ) and release probability were not strongly correlated with the distance between apposition and the GC somata ( $r=0.57$ and -0.18 , respectively; neither correlation was statistically significant).
Estimation of synaptic convergence required to trigger spiking in granule cells

Many studies suggest that dendritic depolarization is a key signal that triggers GABA release from granule cells by opening voltagegated $\mathrm{Ca}^{2+}$ channels (Isaacson and Strowbridge, 1998; Isaacson, 
2001). There are multiple potential routes to achieve dendritic depolarization in GCs, including evidence for localized sites of $\mathrm{Ca}^{2+}$ or $\mathrm{Na}^{+}$channel activation within apical dendrites (Egger et al., 2003, 2005; Zelles et al., 2006, Bywalez et al., 2015) as well as globally acting $\mathrm{Na}^{+}$-based APs. Halabisky et al. (2000) tested the role of voltage-gated $\mathrm{Na}^{+}$channels in triggering recurrent dendrodendritic inhibition in MCs and found that blockade of TTXsensitive $\mathrm{Na}^{+}$channels in GCs greatly attenuated GABAergic dendrodendritic inhibition evoked by brief MC depolarizations, suggesting that for isolated transient stimuli globally acting GC APs were the critical signal. (Voltage-gated $\mathrm{Na}^{+}$channels in MCs were blocked throughout these experiments by QX-314, which was included in the recording pipette.) We, therefore, asked how effective DD EPSP summation would be in triggering $\mathrm{Na}^{+}$-based APs in GCs. To accomplish this, we first assayed spiking responses evoked by focal glomerular layer stimulation from eight MCs and eight TCs recorded under cell-attached conditions. These discharges $(N=204$ trials $)$ typically included $6.60 \pm 0.45$ spikes within the $400 \mathrm{~ms}$ window considered in our computer simulations (Fig. 7A, example). We next combined experimentally determined MC and TC firing patterns with the properties of DD and cortical feedback synapses in a computational model assessing the number of presynaptic neurons that would need to be active to trigger spiking in GCs. In this model, EPSPs barrages evoked by each presynaptic MC (or TC) spike train are sequentially layered, estimating the membrane depolarization that would occur during EPSP summation during convergent excitation from multiple presynaptic neurons (Fig. $7 B, C$ ). The computational model incorporated a large library of recorded unitary DD EPSP amplitudes, another library of measured DD EPSP latencies, a template DD EPSP response constructed from a composite average from all seven dual WC paired recordings, the measured average release probability $(0.74)$ as well as the composite short-term depression shown in Figure $3 D$. Since the degree of synchrony among different MCs activated by the same odor is variable (Kashiwadani et al., 1999; Shusterman et al., 2011), we assayed a variety of introduced jitters (initial MC/TC spike latency SD varied from 1 to $50 \mathrm{~ms}$ ).

Even under the most synchronous conditions tested $(1 \mathrm{~ms}$ added jitter between discharges in different simultaneously active MCs), our simulations suggest that 25.5 presynaptic neurons would need to be spiking during the same sniff cycle to reliably trigger spiking (at least one AP in 95\% of simulations; Fig. 7D, black plot). Only slightly fewer presynaptic inputs (19.5) would need to be simultaneously active to have a $50 \%$ likelihood of triggering a spike in a GC (Fig. $7 D$, red plot). When more physiology levels of MC firing jitter are introduced (20 ms initial spike latency SD; Kashiwadani et al., 1999; Shusterman et al., 2011), even more presynaptic MCs (28.8) are required to achieve reliably triggering of at least one AP; convergence from 21.7 presynaptic MCs is required to trigger at least one AP in half of the responses. As shown in Figure $7 E$, the large number of simultaneously active presynaptic principal cells required to drive GC spiking results in large part from the short-term plasticity present in DD synapses. Exchanging the facilitating short-term plasticity measured in cortical feedback synapses (Fig. 7E, "PPF") for the short-term depression recorded in DD synapses (Fig. 7E, "PPD") reduced the excitatory convergence required by $\sim 50 \%$ when driven by either MCs or TCs.

The large excitatory convergence required to trigger spiking is especially surprising given the small number of DD synaptic inputs to GCs. On average, GCs form $\sim 65$ spines within the EPL, the lamina where dendrodentrites predominately occur (Price and
Powell, 1970; Greer, 1987; Whitman and Greer, 2007). Therefore, our simulations suggest that sensory stimulation would need to trigger discharges in $\sim 50 \%$ of all presynaptic principal cells to reliably trigger at least one AP in a GC. While that level of synaptic convergence may occur in response to massive sensory stimulation, functional imaging studies (Wachowiak and Cohen, 2001) suggest that most odor responses trigger more sparse patterns of glomerular activity that would appear unlikely to result in these very high degrees of synaptic convergence from presynaptic MCs or TCs.

Including a relatively small number of cortical-like excitatory inputs to GCs (each generating five spikes at $40 \mathrm{~Hz}$ ) with the composite short-term plasticity shown in Figure $3 G$ reduced the number of simultaneously active orthodromic DD inputs required to drive GC spiking (Fig. $7 F$ ). Including seven facilitating cortical inputs reduced the number of active DD inputs required to trigger at least one AP in $50 \%$ of trials by 11.0 presynaptic MCs. As shown in Figure $7 F$, inset, the effectiveness of cortical inputs that were presented within the same simulated respiratory cycle was supralinear, with a larger reduction in the number of presynaptic DD inputs than the number of added cortical inputs. The effectiveness of cortical inputs in lowering the DD synaptic convergence required to trigger spiking was strongly affected by short-term plasticity. Exchanging the normally facilitating shortterm plasticity at cortical inputs for depressing DD short-term plasticity abolished the supralinear behavior of cortical inputs. Including seven cortical inputs with short-term depression only reduced the number of dendrodentrites required to trigger firing in $50 \%$ of trials by an average of 6.9 cells. Simultaneously recruited cortical feedback inputs were effective in lowering the number of presynaptic DD inputs needed to trigger GC spiking over a broad range of MC/piriform cell latencies (Fig. 7G).

\section{Discussion}

In this study, we report for the first time the postsynaptic potentials evoked by APs in OB MCs on their principal local synaptic targets, inhibitory GCs. We make three primary conclusions in this study. First, the MC DD synapse generates a highly variable postsynaptic response with both a high degree of trial-to-trial variability in recordings from individual MC/GC pairs and a large variability in average release probability across the population of $\mathrm{MC} / \mathrm{GC}$ dual recordings. Second, the DD undergoes short-term depression at all physiological MC firing rates, affecting especially the third and subsequent EPSPs in response to presynaptic MC discharges. This short-term depression appears to be reversed during 300-500 ms pauses in MC firing that occur during the basal respiratory cycle. Finally, the relatively small amplitude, response variability, and short-term depression of the DD input to GCs makes it unlikely that these excitatory inputs reliably trigger spikes in GCs. Instead, the properties of DD synaptic inputs likely function to force GCs to respond primarily to concerted excitation from multiple presynaptic MCs.

In addition to the sparse density of DD interconnections, the high frequency of spontaneous EPSPs in GCs makes demonstrating monosynaptic paired connections in the OB more challenging than in cortical regions because of the need to determine whether each MC/GC pair required averaging a large number of trials. However, the high basal rate of EPSPs was helpful in ensuring that the postsynaptic GCs in our connected pairs were all likely fully mature since DD synapses form during the final stages of GC maturation (Carleton et al., 2003; Whitman and Greer, 2007; Kelsch et al., 2008). Our two-photon visualization of the extensive GC dendritic arbor in the seven dual WC pairs also was 
A
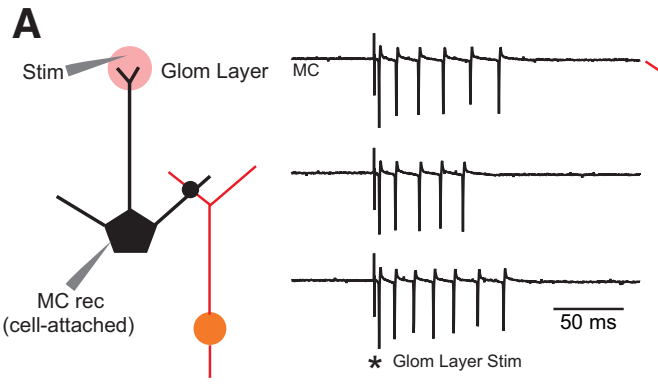

D

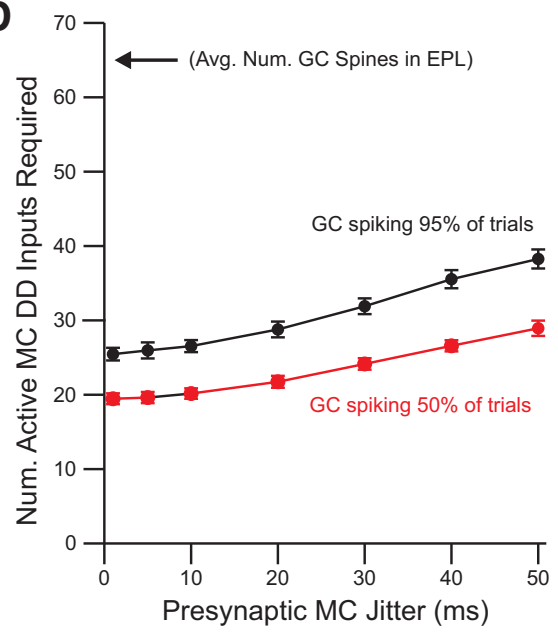

F

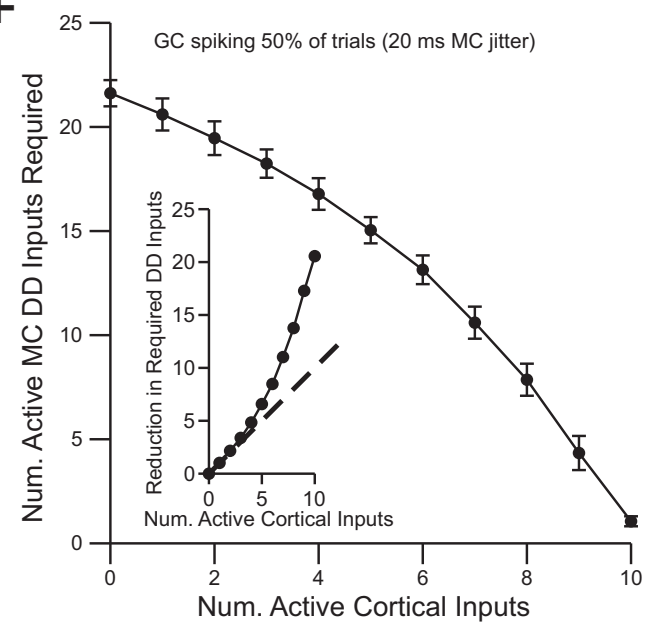

B

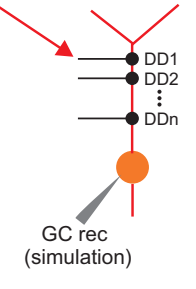

C

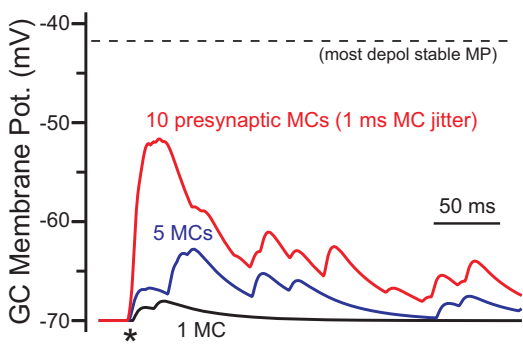

E

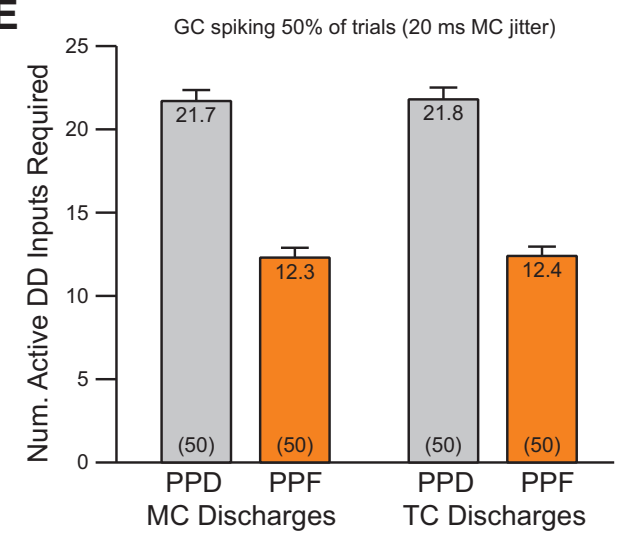

G

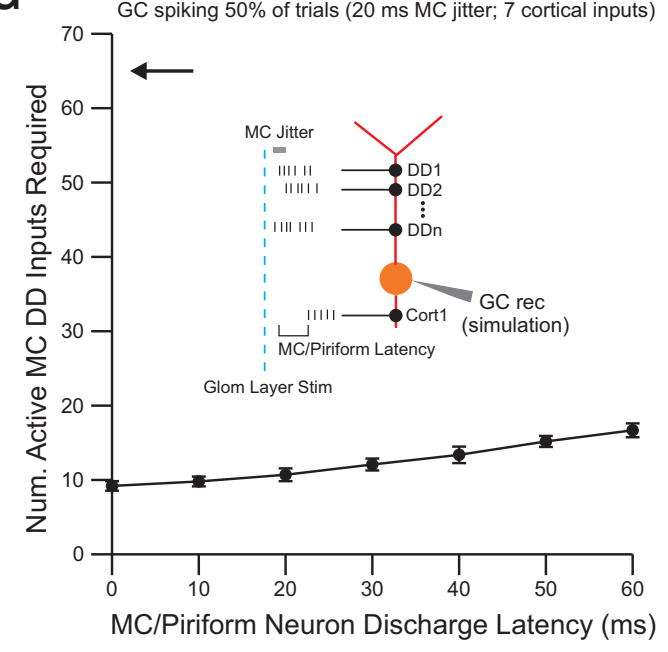

Figure 7. Computation simulations to estimate synaptic convergence required to trigger spiking in granule cells. $A$, Example MC firing patterns evoked by focal on-beam glomerular (Glom) stimulation (Stim) and recorded (rec) using a cell-attached configuration. Schematic diagram of experiment shown in left panel. Three responses to the same stimulus shown in right panel. $B$, Diagram of computation simulation of DD EPSP summation. C, Example simulation trials showing summation from 1 (black trace), 5 (blue), and 10 (red) presynaptic MCs. Asterisk indicates the time of glomerular layer stimulus used to trigger the MC discharges. Dashed line represents the most depolarized stable membrane potential recorded in GCs $(-42.0 \mathrm{mV} ; N=6$ cells). $\boldsymbol{D}$, Plot relationship between jitter across presynaptic MC ensembles (SD of latency to first AP) and the number (Num.) of DD EPSP inputs required to trigger spiking in 50\% (red trace) or 95\% (black trace) of trials. Arrow along the $y$-axis indicates the average (Avg.) number of DD inputs available (mean number of spines in the external plexiform layer estimated from published work). $\boldsymbol{E}$, Plot of the number of DD EPSP inputs required to trigger GC spiking in 50\% of trials using MC (left) or TC (right) cell-attached discharges with 20 ms ensemble jitter. Simulations used either the short-term plasticity recorded in DD pairs ("PPD," Fig. 3D) or from focal stimulation of cortical feedback EPSPs ("PPF," Fig. 3G). F, Plot of the decrease in the number of DD EPSPs required to trigger GC spiking in $50 \%$ of trials as more cortical feedback EPSPs are included ( $20 \mathrm{~ms} \mathrm{MC} \mathrm{ensemble} \mathrm{jitter).} \mathrm{Inset} \mathrm{shows} \mathrm{the} \mathrm{same} \mathrm{data} \mathrm{replotted} \mathrm{as} \mathrm{a} \mathrm{reduction} \mathrm{in} \mathrm{the} \mathrm{number} \mathrm{of} \mathrm{DD} \mathrm{inputs} \mathrm{required} \mathrm{to} \mathrm{trigger} \mathrm{spiking}$ with additional cortical feedback EPSP inputs. Dashed line at unity (1:1 relationship). $G$, Plot of the relationship between latency differences in MC and piriform cortical inputs versus the number of DD EPSP inputs required to trigger GC spiking in 50\% of trials (20 ms MC ensemble jitter; number of piriform cortical inputs fixed at 7).

consistent with mature GCs, as was the ability of all postsynaptic GCs to discharge repetitively. Immature GCs typically fail to generate repetitive large-amplitude APs (Carleton et al., 2003). Rundown and other nonspecific effects of intracellular dialysis represent other potential concerns when studying synapses formed by presynaptic dendrites using whole-cell patch-clamp recording. However, dialysis is not an issue with the loose-patch configuration. The similarity of the results we obtained with both 
recording modes suggests that our results are not strongly influenced by artifacts from whole-cell recording and that the large range of release probabilities we find at DD synapses (from 0.5 to 0.94 in pairs with LP MC recordings; 0.39 to 0.97 in dual WC pairs), is not likely to be attributable to other recording artifacts. Instead, the variation in this key parameter may reflect different degrees of long-term synaptic plasticity and/or variation in functional properties of presynaptic proteins that govern glutamate release. Since GC-related circuits are continuously integrated in the $\mathrm{OB}$, it is possible that variations in GC EPSP properties also reflect different degrees of spine maturation (Panzanelli et al., 2009; Katagiri et al., 2011).

To our knowledge, there have only been two previous reports that directly recorded DD synaptic excitation of GCs using paired recordings (Isaacson, 2001; Kato et al., 2013). Since glutamate release was triggered by relatively long-duration $(10 \mathrm{~ms})$ voltageclamp steps in the study by Isaacson (2001), it was not possible to define the fundamental properties of DD synapses such as unitary amplitude or release probability. Defining these properties was a central goal in this study and the motivation for using the current-clamp recording configuration in both presynaptic and postsynaptic neurons. The study by Kato et al. (2013) recorded from presynaptic MCs under current-clamp conditions but only quantified the MC/GC connection probability (4\% connection probability based on two connected pairs, neither of which showed reciprocal connections). Several studies have attempted to define the pattern of short-term plasticity as DD excitatory synapses and have generally found evidence for synaptic depression. Two studies from our group (Balu and Strowbridge, 2007; Gao and Strowbridge, 2009) used two-photon-guided minimal stimulation to focally activate presynaptic processes on distal GC dendrites in the EPL. Our results with paired recordings are generally consistent with these previous findings albeit with less pronounced depression on the second EPSP in the train than observed using extracellular stimulation. This relatively small difference in short-term plasticity resulted in a large $(33 \%)$ increase in the number of simultaneously active presynaptic MCs required to reliably trigger at least one GC AP (38 vs 29 MCs required using estimates of the short-term plasticity from paired recordings). While further work will be required to understand the basis of the larger synaptic depression observed with extracellular stimulation, it could reflect the recruitment of additional circuit mechanisms, such as coactivated inhibitory axons that could have activated presynaptic $\mathrm{GABA}_{\mathrm{B}}$ receptors on MCs. The consistent short-term depression we find in DD synapses contrasts with facilitating responses typically recorded in pyramidal cells in piriform cortex following lateral olfactory tract stimulation (Franks and Isaacson, 2006; Suzuki and Bekkers, 2006; Stokes and Isaacson, 2010). This target-specific variation in the short-term plasticity associated with synapses onto different cell types innervated by MCs is consistent with previous work establishing nonfacilitating inputs from MC nonpyramidal cell types in piriform cortex [neutral paired-pulse ratio in recordings from layer 1a interneurons (Stokes and Isaacson, 2010) and short-term depression in semilunar cells (Suzuki and Bekkers, 2006)].

In addition to the prior two-photon-guided minimal stimulation work, other studies have reported presumptive DD synaptic responses based on higher-intensity (supraminimal) extracellular stimulation, primarily with the goal of determining the glutamate receptor subtypes expressed on GCs and the mechanism of GABA release from GCs (Isaacson and Strowbridge, 1998; Schoppa et al., 1998; Chen et al., 2000). Several other studies (Dietz and Murthy, 2005; Schoppa, 2006) explored GC responses evoked by supraminimal stimulation in different OB layers; one of these studies (Dietz and Murthy, 2005) found a mixture of depressing and facilitating responses, a result likely attributable to the activation of both DD and cortical inputs onto GCs. Our results demonstrating that short-term depression at DD synapses recovers during pauses in MC firing associated the basal respiratory rhythm is consistent with the results of the study by Dietz and Murthy (2005), which found little depression in evoked responses following pauses of $>400 \mathrm{~ms}$. While our LP recordings used trains of brief voltage pulses applied to the MC, in principal more complex phasic stimuli are possible and could be optimized to resonate with $\mathrm{MC}$ intrinsic currents to trigger repeatable high-frequency MC discharges. This approach would be better suited for determining the kinetics of recovery from short-term depression at DD synapses since the triggering of spikes using voltage transients required continual adjustment of the stimulus voltage.

Granule cells are the primary source of inhibition onto principal cells and, therefore, play a central role in shaping the output of the OB. The results from this study show directly for the first time that the main excitatory drive onto these interneurons is weak (low unitary amplitude, variable release probability with short-term depression throughout the physiological range of MC firing frequencies). These synaptic properties of DD synapses likely function to minimize the ability of individual presynaptic MCs or TCs to strongly depolarize postsynaptic GCs, enforcing a requirement for the activation of a relatively large subset of all presynaptic MCs (and/or TCs) to trigger spiking within each sniff cycle. Without these synaptic properties, the prolonged discharges of MCs typically generated in response to sensory stimulation (Shusterman et al., 2011; Sirotin et al., 2015) would lead to robust EPSP summation and more frequent GC discharges. One important consequence of these synaptic properties, therefore, is likely the ensuring of sparse GC firing, as observed in vivo (Cazakoff et al., 2014; Fukunaga et al., 2014). The absence of the inverse correlation between unitary EPSP amplitude and apposition distance along the postsynaptic GC dendrite - expected from electrotonic cable attenuation-likely reflects dendritic amplification of DD input. Similar "response-normalizing" intrinsic properties have been reported in neocortical (Stuart et al., 1997) and hippocampal pyramidal cells (Golding and Spruston, 1998; Losonczy and Magee, 2006) and may function to minimize biases against presynaptic MCs that innervate relatively distal dendritic sites. Previous studies demonstrated the ability of GC apical dendrites to generate spikelets and low-threshold $\mathrm{Ca}^{2+}$ responses (Egger et al., 2003; Zelles et al., 2006; Bywalez et al., 2015), potential cellular mechanisms for amplifying distal DD inputs.

Given that DD synapses appear to restrict GC spiking response periods when there is synchronous activation of multiple presynaptic MCs or TCs within a sniff cycle, how does DD-mediated inhibition facilitate odor discrimination? Several mechanisms are possible. First, GC-mediated inhibition may be restricted to very infrequent times when there is relatively massive activation of nearby glomerular columns, which generate enough synchronous excitation through DD inputs to trigger spiking ( $~ 50 \%$ of all DD inputs onto a single GC). This scenario seems unlikely given the behavioral evidence that revealed the role of GC circuits in facilitating fine odor discrimination (Abraham et al., 2010). The relatively weak odor stimuli used in that study would be unlikely to trigger the massive activation of nearby glomeruli needed for strong orthrodromic (via DD synapses) activation of GCs. More likely, GC spiking occurs when GCs are excited through a combination of DD and cortical feedback synaptic inputs. Our experimental and computer simulation results suggest that including 
relatively few cortical inputs can have a disproportionate effect on reducing the number of DD inputs required to trigger GC spiking; a GC that was excited through seven cortical synapses spiked reliably in response $\sim 50 \%$ fewer DD inputs than a GC that was excited solely through orthodromic DD inputs. Our simulations also revealed a relatively broad temporal window for coincident cortical and DD input to facilitate GC spiking within the same sniff cycle, corresponding to experimental estimates of a range of delays between MCs and piriform neuronal discharges (Zhan and Luo, 2010; Shusterman et al., 2011; Miura et al., 2012). The sparse connectivity between MCs and GCs ( 3\% in our study; $4 \%$ in the study by Kato et al., 2013) and the weak degree of dendrodendritic EPSP summation may function together to ensure that individual GCs generate highly odor-selective discharges when specific glomerular (and likely piriform cortical) active patterns are present. Odor-specific GC inhibition could, then, create more odorspecific MC firing patterns by modulating the broadly tuned excitatory input that these principal cells receive from sensory neurons. In addition, our results cannot exclude the possibility that the weaker DD excitation (subthreshold for AP generation) is able to trigger some local GABA release, as suggested by several experimental (Lagier et al., 2004) and computational modeling (Brea et al., 2009) studies, potentially allowing for multiple GC output modes depending on the degree of presynaptic MC synchronization.

\section{References}

Abbott LF, Regehr WG (2004) Synaptic computation. Nature 431:796-803. CrossRef Medline

Abraham NM, Egger V, Shimshek DR, Renden R, Fukunaga I, Sprengel R, Seeburg PH, Klugmann M, Margrie TW, Schaefer AT, Kuner T (2010) Synaptic inhibition in the olfactory bulb accelerates odor discrimination in mice. Neuron 65:399-411. CrossRef Medline

Balu R, Strowbridge BW (2007) Opposing inward and outward conductances regulate rebound discharges in olfactory mitral cells. J Neurophysiol 97:1959-1968. CrossRef Medline

Balu R, Larimer P, Strowbridge BW (2004) Phasic stimuli evoke precisely timed spikes in intermittently discharging mitral cells. J Neurophysiol 92:743-753. CrossRef Medline

Balu R, Pressler RT, Strowbridge BW (2007) Multiple modes of synaptic excitation of olfactory bulb granule cells. J Neurosci 27:5621-5632. CrossRef Medline

Barbour B, Isope P (2000) Combining loose cell-attached stimulation and recording. J Neurosci Methods 103:199-208. CrossRef Medline

Bartel DL, Rela L, Hsieh L, Greer CA (2015) Dendrodendritic synapses in the mouse olfactory bulb external plexiform layer. J Comp Neurol 523:1145-1161. CrossRef Medline

Brea JN, Kay LM, Kopell NJ (2009) Biophysical model for gamma rhythms in the olfactory bulb via subthreshold oscillations. Proc Natl Acad Sci U S A 106:21954-21959. CrossRef Medline

Bywalez WG, Patirniche D, Rupprecht V, Stemmler M, Herz AV, Pálfi D, Rózsa B, Egger V (2015) Local postsynaptic voltage-gated sodium channel activation in dendritic spines of olfactory bulb granule cells. Neuron 85:590-601. CrossRef Medline

Carleton A, Petreanu LT, Lansford R, Alvarez-Buylla A, Lledo PM (2003) Becoming a new neuron in the adult olfactory bulb. Nat Neurosci 6:507518. CrossRef Medline

Cazakoff BN, Lau BY, Crump KL, Demmer HS, Shea SD (2014) Broadly tuned and respiration-independent inhibition in the olfactory bulb of awake mice. Nat Neurosci 17:569-576. CrossRef Medline

Chen WR, Xiong W, Shepherd GM (2000) Analysis of relations between NMDA receptors and GABA release at olfactory bulb reciprocal synapses. Neuron 25:625-633. CrossRef Medline

Cury KM, Uchida N (2010) Robust odor coding via inhalation-coupled transient activity in the mammalian olfactory bulb. Neuron 68:570-585. CrossRef Medline

Davison IG, Katz LC (2007) Sparse and selective odor coding by mitral/tufted neurons in the main olfactory bulb. J Neurosci 27:2091-2101. CrossRef Medline

de Olmos J, Hardy H, Heimer L (1978) The afferent connections of the main and the accessory olfactory bulb formations in the rat: an experimental HRP-study. J Comp Neurol 181:213-244. CrossRef Medline

Desmaisons D, Vincent JD, Lledo PM (1999) Control of action potential timing by intrinsic subthreshold oscillations in olfactory bulb output neurons. J Neurosci 19:10727-10737. Medline

Dietz SB, Murthy VN (2005) Contrasting short-term plasticity at two sides of the mitral-granule reciprocal synapse in the mammalian olfactory bulb. J Physiol 569:475-488. CrossRef Medline

Egger V, Svoboda K, Mainen ZF (2003) Mechanisms of lateral inhibition in the olfactory bulb: efficiency and modulation of spike-evoked calcium influx into granule cells. J Neurosci 23:7551-7558. Medline

Egger V, Svoboda K, Mainen ZF (2005) Dendrodendritic synaptic signals in olfactory bulb granule cells: local spine boost and global low-threshold spike. J Neurosci 25:3521-3530. CrossRef Medline

Eyre MD, Antal M, Nusser Z (2008) Distinct deep short-axon cell subtypes of the main olfactory bulb provide novel intrabulbar and extrabulbar GABAergic connections. J Neurosci 28:8217-8229. CrossRef Medline

Eyre MD, Kerti K, Nusser Z (2009) Molecular diversity of deep short-axon cells of the rat main olfactory bulb. Eur J Neurosci 29:1397-1407. CrossRef Medline

Franks KM, Isaacson JS (2006) Strong single-fiber sensory inputs to olfactory cortex: implications for olfactory coding. Neuron 49:357-363. CrossRef Medline

Friedrich RW, Laurent G (2001) Dynamic optimization of odor representations by slow temporal patterning of mitral cell activity. Science 291:889894. CrossRef Medline

Fukunaga I, Berning M, Kollo M, Schmaltz A, Schaefer AT (2012) Two distinct channels of olfactory bulb output. Neuron 75:320-329. CrossRef Medline

Fukunaga I, Herb JT, Kollo M, Boyden ES, Schaefer AT (2014) Independent control of gamma and theta activity by distinct interneuron networks in the olfactory bulb. Nat Neurosci 17:1208-1216. CrossRef Medline

Gao Y, Strowbridge BW (2009) Long-term plasticity of excitatory inputs to granule cells in the rat olfactory bulb. Nat Neurosci 12:731-733. CrossRef Medline

Golding NL, Spruston N (1998) Dendritic sodium spikes are variable triggers of axonal action potentials in hippocampal CA1 pyramidal neurons. Neuron 21:1189-1200. CrossRef Medline

Greer CA (1987) Golgi analyses of dendritic organization among denervated olfactory bulb granule cells. J Comp Neurol 257:442-452. CrossRef Medline

Guthrie KM, Anderson AJ, Leon M, Gall C (1993) Odor-induced increases in c-fos mRNA expression reveal an anatomical "unit" for odor processing in olfactory bulb. Proc Natl Acad Sci U S A 90:3329-3333. CrossRef Medline

Haberly LB, Price JL (1978) Association and commissural fiber systems of the olfactory cortex of the rat. J Comp Neurol 178:711-740. CrossRef Medline

Halabisky B, Friedman D, Radojicic M, Strowbridge BW (2000) Calcium influx through NMDA receptors directly evokes GABA release in olfactory bulb granule cells. J Neurosci 20:5124-5134. Medline

Hasselmo ME, Bower JM (1990) Afferent and association fiber differences in short-term potentiation in piriform (olfactory) cortex of the rat. J Neurophysiol 64:179-190. Medline

Isaacson JS (2001) Mechanisms governing dendritic gamma-aminobutyric acid (GABA) release in the rat olfactory bulb. Proc Natl Acad Sci U S A 98:337-342. CrossRef Medline

Isaacson JS, Strowbridge BW (1998) Olfactory reciprocal synapses: dendritic signaling in the CNS. Neuron 20:749-761. CrossRef Medline

Jahr CE, Nicoll RA (1980) Dendrodendritic inhibition: demonstration with intracellular recording. Science 207:1473-1475. CrossRef Medline

Jonas P, Major G, Sakmann B (1993) Quantal components of unitary EPSCs at the mossy fibre synapse on CA3 pyramidal cells of rat hippocampus. J Physiol 472:615-663. CrossRef Medline

Kashiwadani H, Sasaki YF, Uchida N, Mori K (1999) Synchronized oscillatory discharges of mitral/tufted cells with different molecular receptive ranges in the rabbit olfactory bulb. J Neurophysiol 82:1786-1792. Medline

Katagiri H, Pallotto M, Nissant A, Murray K, Sassoè-Pognetto M, Lledo PM (2011) Dynamic development of the first synapse impinging on adult-born neurons in the olfactory bulb circuit. Neural Syst Circuits 1:6. CrossRef Medline

Kato HK, Gillet SN, Peters AJ, Isaacson JS, Komiyama T (2013) Parvalbumin- 
expressing interneurons linearly control olfactory bulb output. Neuron 80 : 1218-1231. CrossRef Medline

Kelsch W, Lin CW, Lois C (2008) Sequential development of synapses in dendritic domains during adult neurogenesis. Proc Natl Acad Sci U S A 105:16803-16808. CrossRef Medline

Lagier S, Carleton A, Lledo PM (2004) Interplay between local GABAergic interneurons and relay neurons generates gamma oscillations in the rat olfactory bulb. J Neurosci 24:4382-4392. CrossRef Medline

Losonczy A, Magee JC (2006) Integrative properties of radial oblique dendrites in hippocampal CA1 pyramidal neurons. Neuron 50:291-307. CrossRef Medline

Lowe G (2002) Inhibition of backpropagating action potentials in mitral cell secondary dendrites. J Neurophysiol 88:64-85. Medline

Margrie TW, Schaefer AT (2003) Theta oscillation coupled spike latencies yield computational vigour in a mammalian sensory system. J Physiol 546:363-374. CrossRef Medline

Miles R, Wong RK (1984) Unitary inhibitory synaptic potentials in the guineapig hippocampus in vitro. J Physiol 356:97-113. CrossRef Medline

Miles R, Wong RK (1986) Excitatory synaptic interactions between CA3 neurones in the guinea-pig hippocampus. J Physiol 373:397-418. CrossRef Medline

Miura K, Mainen ZF, Uchida N (2012) Odor representations in olfactory cortex: distributed rate coding and decorrelated population activity. Neuron 74:1087-1098. CrossRef Medline

Murphy GJ, Darcy DP, Isaacson JS (2005) Intraglomerular inhibition: signaling mechanisms of an olfactory microcircuit. Nat Neurosci 8:354-364. CrossRef Medline

Najac M, Sanz Diez A, Kumar A, Benito N, Charpak S, De Saint Jan D (2015) Intraglomerular lateral inhibition promotes spike timing variability in principal neurons of the olfactory bulb. J Neurosci 35:4319-4331. CrossRef Medline

Nakashima M, Mori K, Takagi SF (1978) Centrifugal influence on olfactory bulb activity in the rabbit. Brain Res 154:301-306. CrossRef Medline

Panzanelli P, Bardy C, Nissant A, Pallotto M, Sassoè-Pognetto M, Lledo PM, Fritschy JM (2009) Early synapse formation in developing interneurons of the adult olfactory bulb. J Neurosci 29:15039-15052. CrossRef Medline

Pressler RT, Strowbridge BW (2006) Blanes cells mediate persistent feedforward inhibition onto granule cells in the olfactory bulb. Neuron 49:889904. CrossRef Medline

Pressler RT, Rozman PA, Strowbridge BW (2013) Voltage-dependent intrinsic bursting in olfactory bulb Golgi cells. Learn Mem 20:459-466. CrossRef Medline

Price JL, Powell TP (1970) The synaptology of the granule cells of the olfactory bulb. J Cell Sci 7:125-155. Medline

Rall W, Shepherd GM, Reese TS, Brightman MW (1966) Dendrodendritic synaptic pathway for inhibition in the olfactory bulb. Exp Neurol 14:4456. CrossRef Medline
Ramon y Cajal S (1911) Histologie du systeme nerveux de l'homme et des vertebres. Paris: Maloine.

Schoppa NE (2006) AMPA/kainate receptors drive rapid output and precise synchrony in olfactory bulb granule cells. J Neurosci 26:12996-13006. CrossRef Medline

Schoppa NE, Kinzie JM, Sahara Y, Segerson TP, Westbrook GL (1998) Dendrodendritic inhibition in the olfactory bulb is driven by NMDA receptors. J Neurosci 18:6790-6802. Medline

Shepherd GM (2003) The synaptic organization of the brain. Oxford UP.

Shusterman R, Smear MC, Koulakov AA, Rinberg D (2011) Precise olfactory responses tile the sniff cycle. Nat Neurosci 14:1039-1044. CrossRef Medline

Sirotin YB, Shusterman R, Rinberg D (2015) Neural coding of perceived odor intensity. eNeuro 2:e0083-15.2015 1-16. CrossRef Medline

Soucy ER, Albeanu DF, Fantana AL, Murthy VN, Meister M (2009) Precision and diversity in an odor map on the olfactory bulb. Nat Neurosci 12:210-220. CrossRef Medline

Stokes CC, Isaacson JS (2010) From dendrite to soma: dynamic routing of inhibition by complementary interneuron microcircuits in olfactory cortex. Neuron 67:452-465. CrossRef Medline

Strowbridge BW, Pressler RT (2017) A simplified electronic circuit for combined single-cell stimulation and recording using loose cell-attached electrodes. bioRxiv. Advance online publication. Retrieved October 24, 2017. doi:10.1101/191718. CrossRef

Stuart G, Schiller J, Sakmann B (1997) Action potential initiation and propagation in rat neocortical pyramidal neurons. J Physiol 505:617-632. CrossRef Medline

Suzuki N, Bekkers JM (2006) Neural coding by two classes of principal cells in the mouse piriform cortex. J Neurosci 26:11938-11947. CrossRef Medline

Wachowiak M, Cohen LB (2001) Representation of odorants by receptor neuron input to the mouse olfactory bulb. Neuron 32:723-735. CrossRef Medline

White J, Hamilton KA, Neff SR, Kauer JS (1992) Emergent properties of odor information coding in a representational model of the salamander olfactory bulb. J Neurosci 12:1772-1780. Medline

Whitman MC, Greer CA (2007) Synaptic integration of adult-generated olfactory bulb granule cells: basal axodendritic centrifugal input precedes apical dendrodendritic local circuits. J Neurosci 27:9951-9961. CrossRef Medline

Zelles T, Boyd JD, Hardy AB, Delaney KR (2006) Branch-specific $\mathrm{Ca}^{2+}$ influx from $\mathrm{Na}^{+}$-dependent dendritic spikes in olfactory granule cells. J Neurosci 26:30-40. CrossRef Medline

Zhan C, Luo M (2010) Diverse patterns of odor representation by neurons in the anterior piriform cortex of awake mice. J Neurosci 30:16662-16672. CrossRef Medline 